\title{
Lymphoid origin of a lineage of intrinsically activated plasmacytoid dendritic cell in mice and humans
}

Joseph D. Dekker ${ }^{\wedge}$, Catherine Rhee ${ }^{2}$, Zicheng $\mathrm{Hu}^{2}$, Bum-Kyu Lee ${ }^{2}$, Jiwon Lee ${ }^{1}$, Vishwanath R. Iyer ${ }^{2}$, Lauren I. R. Ehrlich ${ }^{2}$, George Georgiou ${ }^{1,2}$, Haley O. Tucker ${ }^{2}$, and Gregory C. Ippolito ${ }^{2^{\wedge}}$

${ }^{1}$ Department of Chemical Engineering, The University of Texas at Austin, Austin TX, USA.

${ }^{2}$ Department of Molecular Biosciences, The University of Texas at Austin, Austin TX, USA.

${ }^{\wedge}$ Corresponding Authors:

Joseph D. Dekker, Department of Chemical Engineering, The University of Texas at Austin, 1 University Station A5000, Austin TX 78712, USA. ORCID: orcid.org/00000002-2068-3529 Phone: (512) 232-4104; Fax (512) 471-7060; E-mail: joedekk@utexas.edu

Haley O. Tucker, Department of Molecular Biosciences. The University of Texas at Austin, 1 University Station A5000, Austin TX 78712, USA. Phone: (512) 475-7706; Fax (512) 475-7707; E-mail: haleytucker@austin.utexas.edu

Gregory C. Ippolito, Department of Molecular Biosciences. The University of Texas at Austin, 1 University Station A5000, Austin TX 78712, USA. Phone: (512) 232-4103; Email: gci@mail.utexas.edu

Running Title: $\mathrm{pDC}$ development from common lymphoid progenitors 
We identified a mouse pDC lineage derived exclusively from the common lymphoid progenitor (CLP) that is dependent on expression of Bcl1a. CLP-derived pDC have a unique gene expression profile that includes hallmark B cell genes not normally expressed in pDCs and therefore we refer to this lineage as "B-pDCs." Unlike classical $\mathrm{pDC}, \mathrm{B}-\mathrm{pDC}$ express an inherent activation signature, localize preferentially to secondary lymphoid organs and expand more robustly and also induce increased $\mathrm{T}$ cell proliferation relative to classical pDCs following Toll-like receptor 9 (TLR9) engagement. B-pDCs lack IFN- $\alpha$ secretion but instead express a distinct cytokine profile and display high levels of the cell-surface receptor tyrosine kinase Axl. Murine B-pDCs represent a CLPderived DC lineage that is genetically, phenotypically, and functionally homologous to an $\mathrm{AXL}^{+} \mathrm{DC}$ subtype recently discovered in human blood ${ }^{1-4}$.

Plasmacytoid dendritic cells (pDCs) specialize in the production of type I interferons (IFNs) and promote antiviral immune responses following engagement of pattern recognition receptors. They have been implicated in the pathogenesis of autoimmune diseases that are characterized by a type I IFN signature (notably, IFN- $\alpha$ ), yet $\mathrm{pDC}$ also can induce tolerogenic immune responses ${ }^{5-8}$. Remarkably, considering the interest in $\mathrm{pDC}$ and their clinical significance, our understanding of $\mathrm{pDC}$ lineage derivation remains muddled. The transcription factor TCF4 is required for $\mathrm{pDC}$ development and for lineage identity ${ }^{9-11}$. TCF4 is a component of a multiprotein complex that includes both positive and negative regulators ${ }^{6,12}$. One of these components, the transcription factor $B c l 11 a$, which is also essential for B cell development ${ }^{13-15}$, induces 
Tcf4 expression and initiates a positive feedback loop with Tcf4 to maintain pDC lineage commitment and function ${ }^{14-16}$.

Unlike their conventional dendritic cell (cDC) counterparts, pDCs express multiple other transcriptional regulators and markers associated with B-lymphocyte development in addition to Bcl11a (e.g. B220, SpiB) ${ }^{17,18}$. These features, along with established generation of $\mathrm{pDC}$ from myeloid restricted precursors, have made it difficult to define $\mathrm{pDC}$ lineage affiliation ${ }^{11,17,19,20}$ leading to the hypothesis that $\mathrm{pDC}$ may have distinct origins derived from either the Common Lymphoid Progenitor (CLP) or the Common Myeloid Progenitor $(\mathrm{CMP})^{18}$. Beyond the enigmatic nature of their lineage derivation, pDCs with different functional attributes (e.g. variable IFN- $\alpha$ expression levels) or different surface markers (e.g. $\mathrm{Cd}_{1} 9^{+} \mathrm{pDCs}$ detected in tumor-draining lymph node) have also been identified ${ }^{17,21-23}$. Recently, a novel dendritic cell (DC) population with pDC-like properties which can be identified by expression of the receptor tyrosine kinase AXL $\left(\mathrm{AXL}^{+} \mathrm{DC}\right)$ was discovered in human blood ${ }^{1-4}$. While $\mathrm{AXL}^{+}$DCs express many "classical" pDC markers (CD123, BDCA2/CD303) they also express the Ig-like lectins SIGLEC1 and SIGLEC6, and the activation marker CD86 ${ }^{1}$. In a separate study ${ }^{2}$ $\mathrm{AXL}^{+}$DCs were shown to be $\mathrm{CD}^{+}$and $\mathrm{CD} 81^{+}$, two glycoproteins normally associated with the B cell receptor (BCR) signaling complex. The origin, exact nature and lineage of the $\mathrm{AXL}^{+}$pDC-like population is currently unknown. Here, we report the identification of a murine, lymphoid-derived counterpart of the human $\mathrm{AXL}^{+} \mathrm{DC}$ subset and demonstrate an in vivo requirement for Bcl11a in its transcriptional specification.

We previously demonstrated that conditional deletion of Bcllla in the hematopoietic stem cell (HSC) compartment mediated by $V a v-1$-Cre or by inducible 
Mx1-Cre recombinase results in complete abolishment of pDC development ${ }^{14}$. Next, spurred by previous speculation of $\mathrm{pDC}$ origin from the CLP ${ }^{17,20}$, we selectively deleted floxed (F) Bcll1a alleles in the late CLP stage ${ }^{24,25}$ mediated by mb1-Cre in vivo. Expression of the $m b 1$ gene $(\mathrm{Cd} 79 \mathrm{a})$ begins at the Ly6d ${ }^{+}$CLP stage, in B-cell-biased lymphoid progenitor (BLPs) ${ }^{26}$, downstream of Ly6d $\mathrm{d}^{-}$CLPs (Fig. S1). Bcl11 $a^{F / F} m b 1-C r e$ mice $(\mathrm{cKO})$ and littermate controls were examined for $\mathrm{pDC}$ frequencies among nucleated cells in the bone marrow (BM). B $220^{+} \mathrm{Pdcal}^{+} \mathrm{pDCs}$ were consistently and significantly reduced by an average of $\sim 25 \%(24.8 \pm 2.4 \%)$ in the $\mathrm{cKO}$ mice relative to littermates (Fig. 1a). A near complete loss of mature recirculating B cells (B220 $\left.{ }^{\text {hi }} \mathrm{Pdca}{ }^{-}\right)$served as a gauge of mb1-Cre deletion efficiency. Additionally, immature B cell numbers were reduced by $>50 \%$ in the KO mice (Fig. 1a, S2).

Next, we transferred BM from either Bcl11a-sufficient reporter control mice (mb1-Cre-YFP) or Bcll1a-deficient cKO mice $\left(B c l 11 a^{F / F} m b 1-C r e-Y F P\right)$ into lethally irradiated $\mathrm{C} 57 \mathrm{BL} / 6$ recipients. After 8 weeks, $<6 \%$ of B cells in the spleens of $m b 1-C r e-$ YFP recipients were $\mathrm{YFP}^{-}$, confirming elimination of recipient hematopoiesis (Fig. 1b). As expected, Bcll1 $a^{F / F} m b 1-C r e-Y F P$ BM resulted in significantly reduced B cell and pDC cellularity compared to mb1-Cre-YFP controls, whereas Bcl11a-sufficient (YFP ${ }^{-}$) pDC persisted (Fig. 1b and c, representative plots Fig. S2). Approximately 1/3 of pDCs in the spleen of wild-type chimeras were $\mathrm{YFP}^{+}$compared to only 1/5 in BM (Fig. 1d). This increased fraction of $\mathrm{YFP}^{+} \mathrm{pDCs}$ in the spleen suggests that CLP-derived pDC preferentially home to that organ. Other hematopoietic lineages were capable of development in normal numbers and contain a paucity of $\mathrm{YFP}^{+}$cells (Fig. 1e). Of note, Bcl11a-deficient progenitors yielded higher splenic $\mathrm{T}$ cell chimerism at the expense of $\mathrm{B}$ 
cells and pDCs, with $\mathrm{T}$ cells being $<2 \% \mathrm{YFP}^{+}$. This indicated that $m b 1$-cre expression occurs subsequent to T-B lineage divergence, consonant with previous observations ${ }^{26}$ and our $m b 1$-cre progenitor analysis in which $\mathrm{YFP}^{+}$cells are confined to CLP stage (Fig. S1).

Collectively, these results provide in vivo evidence for Bcl11a-dependent and BLP-derived pDCs (generated downstream of CLP) which populate the BM and periphery of adult mice. Because of their exclusive lymphoid derivation post T-B bifurcation, we were prompted hereafter to refer to this pDC lineage as "B-pDC." To further elucidate their phenotype at the genetic level, we performed RNA-seq analyses of purified B-pDC and compared them to classical, myeloid-derived pDC (Fig. 2a). Purity of each population was confirmed as $\mathrm{pDC}$ by RT-PCR of shared pDC markers (Pdcal and Bcl11a) (Fig. S3). While the overall gene expression patterns were highly similar across the two subsets, $\sim 1 \%$ of transcripts ( $\sim 220$ genes) differed significantly ( $q$ value $<$ 0.05, Fig. 2b). Differentially expressed transcripts generated Gene Ontology $(\mathrm{GO})^{27}$ or Panther $^{28}$ terms including "immune response", “inflammatory response", "cell activation", and "regulation of immune response" $\left(\mathrm{p}=1.36 \times 10^{-17}, 2.15 \times 10^{-12}, 3.67 \times 10^{-11}\right.$, and $1.45 \times 10^{-10}$, respectively; Fig. S4). Gene set enrichment analysis (GSEA) revealed elevation of each of these same GO/Panther terms within the B-pDC subset as compared to a pDC-related GSEA control dataset that showed no enrichment (Fig. 2c). Next we compared all genes expressed by both pDC populations to one another and to published ${ }^{29}$ RNA-seq of BM-derived mouse pre-B cells $\left(\mathrm{B} 220^{+} \mathrm{IgM}^{-} \mathrm{Kit}^{-} \mathrm{Cd} 25^{+}\right)$- a post-CLP B cell progenitor (pre-B) population (Fig. 2d and e, S5. pDC and B-pDC expression levels showed a strong correlation to each other relative to $B$ cells $\left(R^{2}\right.$ values $=0.8959,0.4145$, and 0.404, respectively). Detailed analysis of these RNA expression data (Fig. 2e, S5, 
coupled with cell phenotyping by flow cytometry (Fig. 3a and b), showed that B-pDCs express genes critical to early B cell biology. $C d 19$ was expressed at intermediate levels relative to B cells (Fig 2e, S5) and flow cytometry analysis revealed virtually all $\mathrm{YFP}^{+} \mathrm{B}-$ pDC from mb1-Cre-YFP WT mice displayed Cd19 on their surface (Fig. 3a and b). In this same context, pre-B cell receptor components VpreB1 and Igll1/lambda5 were transcriptionally upregulated in B-pDCs (Fig. 2e), analogous to human $\mathrm{AXL}^{+} \mathrm{pDC}^{1}$; however, surface expression of neither protein could be detected by flow cytometry. Likewise, surface expression of BCR components IgM or Cd79a could not be detected by flow cytometry (data not shown). While several key B cell genes are highly expressed in B-pDC, other B-cell defining transcription factors are not (e.g. Pax5, Foxp1, Tcf3, Fig. 2e, S5).

A previously undefined DC subset captured in the conventional CD123 ${ }^{+} \mathrm{BDCA}^{+}$ $\mathrm{pDC}$ gate $\left(\mathrm{AXL}^{+} \mathrm{DC}\right)$ was recently identified in humans by several groups ${ }^{1,2,4}$. This $\mathrm{pDC}$ subset is defined by high expression of $A X L$, SIGLEC1, SIGLEC6, CD2, CD22 CD81, $C D 86$ and $L Y Z$ relative to classical pDC. We found that in mice, all of the homologous genes are also transcribed at elevated levels in the B-pDC compartment relative to classical pDC (Fig. 2e, S5), implying there is a conserved genetic program in common between mouse B-pDC and human $\mathrm{AXL}^{+}$DC. Phenotypic analysis of total $\mathrm{B} 220^{+} \mathrm{Pdcal}^{+}$ cells in the mouse confirmed that $\sim 20 \%$ of pDCs were $\mathrm{Axl}^{+} \mathrm{Siglec}^{+}, \mathrm{Cd}^{+} 6^{+}, \mathrm{Cd} 19^{+}$, and $\mathrm{YFP}^{+}$(Fig. 3b).

Relative to classical $\mathrm{pDC}$, resting $\mathrm{Axl}^{+} \mathrm{B}-\mathrm{pDC}$ express higher levels of activation markers ${ }^{30}$ MHC Class II, Cd83, and Cd86 (Fig 2e, 3a and b) suggesting that they may be primed for immediate response to pro-inflammatory signals. To test this hypothesis, we 
delivered TLR9 ligand (CpG:ODN) into mbl-Cre-YFP mice via tail vein injection and splenic pDC were phenotyped 24 hours later (Fig 3c and d). While both pDC and B-pDC compartments expanded relative to controls, the $\mathrm{YFP}^{+}$B-pDC fraction increased $\sim 3$-fold above that of the $\mathrm{YFP}^{-}$pDC fraction $(\sim 2.7 \mathrm{x}$ and $\sim 7 \mathrm{x}$ expansion, respectively, Fig. 3d). Additionally B-pDC had markedly enhanced expression of MHC class II, Cd83, and Cd86 levels upon activation, (Fig. 3c and d). These results indicate that, relative to classical pDC, B-pDC are intrinsically activated and primed for rapid expansion upon TLR9 engagement.

Cer7 is strongly expressed upon activation of pDC by TLR9 engagement following $\mathrm{CpG}$ stimulation ${ }^{31}$, and such upregulation has been shown to be critical for chemotactic migration of activated DC into lymphoid organs for interaction with $\mathrm{T}$ cells $^{32-34}$. B-pDC showed 4-fold higher basal $C c r 7$ expression compared to classical pDC pDC; Fig. 2e, S5) consistent with their preferential residence in spleen (Fig. 1d). These data further suggest that B-pDC are prepositioned for immediate responses rather than summoned upon infection. Finally, coincident with the tenet that B-pDC may be primed and prepositioned for immediate response to pro-inflammatory signals, we note unexpected and extraordinarily high expression of complement (C1qa, Clqb, and Clqc) and lysozyme ( $L y z 1, L y z 2)$ genes in the B-pDC subset (Fig. S7)—rivaling only that of red pulp or peritoneal cavity resident macrophages ${ }^{35}$. Human $\mathrm{AXL}^{+} \mathrm{DC}$ overexpress these genes too ${ }^{1,4}$.

To confirm the functional phenotype of B-pDC, we tested their ability to secrete cytokines known to be elicited by pDCs after Toll-like receptor (TLR) engagement. Specifically, we tested each pDC lineage for the production of IFN- $\alpha$ or IL-12p40 when 
activated by TLR9-binding CpG oligonucleotides. We sorted B-pDC and pDC, engaged TLR9 with CpG:ODNs for 24 hours and collected supernatant for cytokine specific ELISAs. IFN- $\alpha$ production was almost negligible in B-pDC $(p<0.0001$, Fig. 3e $)$ yet IL$12 \mathrm{p} 40$ production was significantly augmented over $\mathrm{pDC}(\mathrm{p}<0.0001$, Fig. 3f), mirroring the functional phenotype of their human $\mathrm{AXL}^{+}$phenotypic counterparts ${ }^{2}$. That classical pDCs originally were identified as professional type I interferon-producing cells (IPC) ${ }^{36}$ endowed with robust secretory machinery for the abundant secretion of cytokines, we speculate that B-pDC might instead utilize this attribute for copious secretion of alternative immune system modulators which they overexpress, such as C1q and Lyz (Fig. S7). We note that C1q can inhibit pDC production of IFN- $\alpha^{37}$.

To test their ability to expand T lymphocytes in culture, each were incubated with CpG:ODNs and co-cultured with freshly isolated CFSE-labeled lymphocytes. After 6 days, co-cultures were stained for CD3 and CFSE-negative cell percentages were recorded (Fig. 3g). B-pDCs were significantly better at expanding T cells in co-cultures ( $p=0.02$, Fig. $3 \mathbf{g}$ and $\mathbf{h}$ ), mirroring the superior ability of $\mathrm{AXL}^{+} \mathrm{DC}$ to expand lymphocytes in human co-cultures ${ }^{2}$.

Both pDCs and B cells require BCL11A for their development and exhibit gene expression overlap between the two lineages ${ }^{14}$. This suggests that $\mathrm{pDC}$ and $\mathrm{B}$ cells may share transcriptional control mechanisms downstream of BCL11A. We employed ChIPseq in model human cell lines to compare direct BCL11A chromatin-bound target genes and how these gene sets might differ between a pDC line (CAL1) and model B cell lines: (1) the pre-B cell line NALM6; (2) the germinal center Burkitt's lymphoma B cell line RAJI; and (3) the lymphoblastoid B cell line, GM12878 ${ }^{38}$. CAL1 expresses classical pDC 


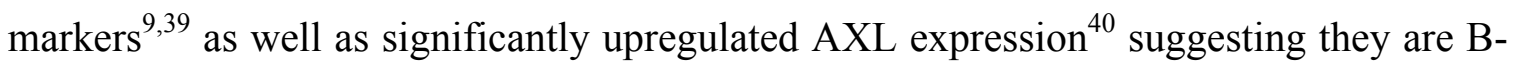
pDC-like. CAL1 was derived from a patient with blastic plasmacytoid dendritic cell neoplasm (BPDCN), a rare and deadly malignancy that uniformly expresses high levels of BCL11A and which, although its ontogeny is unclear, is widely believed to originate from $\mathrm{pDCs}^{9,41,42}$. Indeed, single-cell analysis has confirmed that whereas primary BPDCN malignant cells express several key B cell markers (IGLL1, IGLL5, SPIB) they are most closely related to $\mathrm{pDCs}$ and $\mathrm{AXL}^{+} \mathrm{pDCs}^{1}$. The occupancy pattern of $B C L 11 A$ in CAL1 pDC bore a striking resemblance to its binding distribution in the three human B cell types, with nearly a quarter of all CAL1 targets shared among all B cell lines, including, intriguingly, BCL11A occupancy on its own promoter region in each cell line (Fig 4a and b). In contrast, while B cells and pDC share numerous BCL11A targets, others are bound in a cell context-dependent fashion, including B cell only binding in PAX5, TCF3, and ID3 loci; CAL1 only binding in AXL, SIGLEC1, and IGLL1; and binding across cell types but with non-overlapping peaks in SPIB and ID2 (Fig. 4b).

Dendritic cell-subset biology and development, and the ensuing nomenclature, have long been unclear. Here, we provide definitive evidence in support of the longsuspected "lymphoid past" of pDCs by establishing their ability to arise in vivo from CLP progenitors with $\mathrm{B} / \mathrm{pDC}$ bipotential lineage capacity ${ }^{17-19,43,44}$. Our data suggest that the murine $\mathrm{pDC}$ compartment is bipartite, being comprised of $\mathrm{B}-\mathrm{pDC}$ - diverted from the CLP post T-B bifurcation-as well as myeloid-derived classical pDC. One possible mechanism by which post-CLP $B$ cell to B-pDC diversion might be achieved is suggested by elevated B-pDC expression of transcription factors Id2 and SpiC (Fig. 2e, S5). Differentiation of the classical pDC is blocked by Id 2 repression of Tcf4 activity ${ }^{45}$ 
and driven by $\mathrm{SpiB}^{46}$. During B cell development, SpiC, which is highly related to $\mathrm{SpiB}$, acts to both reduce $\mathrm{B}$ cell numbers ${ }^{47}$ and to oppose SpiB-driven transcriptional regulation $^{48}$. Once formed in the late CLP, mouse B-pDC exhibit additional canonical B cell genes; most notably Cd19, possibly displayed with help from high expression of the membrane tetraspanin $\mathrm{Cd} 81$, which is required for trafficking $\mathrm{Cd} 19$ to the surface in $\mathrm{B}$ cells $^{49}$

Recently, several groups have identified in human blood a new $\mathrm{AXL}^{+} \mathrm{DC}$ subset with distinct functions ${ }^{1,2,4}$. Although defined differently $\left(\mathrm{Axl}^{+} \mathrm{Siglec}^{+} \mathrm{Siglec}^{+1} \mathrm{vs}\right.$. $\left.\mathrm{Axl}^{+} \mathrm{Cd} 2^{\text {hi }} \mathrm{Cd} 81^{+2,4}\right)$, both definitions encompass the mouse B-pDC described here. Our study provides compelling evidence that the murine B-pDC is the homologue of this evolutionarily conserved DC subset. As with its human counterpart ${ }^{3}$, the B-pDC is found at higher frequency in the spleen than in the BM, indicating the possibility they preferentially home to secondary lymphoid organs. The mouse B-pDC also intrinsically express activation markers at higher levels, divide more rapidly after TLR9 engagement, and expand $\mathrm{T}$ cells more rapidly in culture than conventional $\mathrm{pDCs}$, similar to $\mathrm{AXL}^{+}$ $\mathrm{DCs}^{2,4}$. While further functional definition awaits discovery, our work provides a framework for the identification and segregation of the B-pDC lineage (comprising about $1 / 5$ of the total $\mathrm{pDC}$ compartment) from its myeloid-derived counterpart(s). In particular, we have elucidated the genetic, phenotypic, and functional conservation in mouse of the human counterpart $\mathrm{AXL}^{+}$DCs by using a lymphoid conditional knockout of the pDC transcription factor Bcl11a; and we have validated an experimental strategy for enriching $\mathrm{Axl}^{+} \mathrm{DCs}$ in wild-type or $m b 1$-driven reporter mice, thereby providing a useful tool for the continued study of this novel pDC lineage. 
Our observations support the hypothesis that DC functionality derives primarily from ontogeny rather than from tissue environment ${ }^{50}$, exemplified by evolution of a specialized pDC lineage from a lymphoid progenitor. To date, the field of pDC biology has yet to identify a clonogenic progenitor restricted to the pDC compartment and perhaps that is because there is no single clonogenic progenitor for the present definition of $\mathrm{pDC}$ lineage, and that there are, at a minimum, two such progenitors for the $\mathrm{pDC}$ compartment. In the case of the B-pDC, our data suggest such a cell should exist within the late CLP, and may deviate from B cell commitment before or after Ly6d expression, thought to be the earliest marker of B cell specification ${ }^{26}$. Future experiments will address this question via refined cell sorting and expansion of CLP populations from $m b l$-driven reporter mice.

Plasmacytoid dendritic cells are thought to be involved in the pathogenesis of a variety of diseases, from autoimmune diseases to multiple treatment-resistant cancer types. For example, chronic activation of human pDC contributes to systemic lupus erythematosis, systemic sclerosis, and IFN-related autoimmune diseases ${ }^{51,52}$. At the same time pDC have been shown to play an important role in normal immune tolerance as well as induce unwarranted immune tolerance in human cancers ${ }^{51}$. The demarcation of mouse B-pDCs may help clarify the perceived plasticity of the pDC compartment in normal and disease contexts ${ }^{51}$, and provides a new cell for targeted study within the context of autoimmune disease, cancer, and infection models.

\section{Online Methods}

\section{Mice}


Generation of Bcl11a cKO Mice was performed as described ${ }^{14}$. Mbl-Cre deleter and Rosa26-YFP reporter strains were obtained from Jackson labs (catalog \#'s 020505 and 006148 , respectively).

\section{Flow cytometry.}

Analytical cytometry was performed on a FACS Fortessa and sorting was performed on a FACS Aria (BD Biosciences) followed by analysis using FlowJo (Tree Star) software. For sorting prior to RNA collection, BM from 12 mice was prepared from femurs at 6 weeks of age, combined into three groups (4 mice/group), and single-cell suspensions were stained with antigen-specific monoclonal antibodies. Anti-mPDCA1-PE (Miltenyi Biotech), Anti-Cd45R/B220-V605, Anti-Cd19-Alexa Flour 700, Anti-Cd86-APC-Cy7, Anti-I-A/I-E-Pacific Blue, Anti-Cd179a-PE, Anti-IL7Ra-V421, Anti-cKit-PE-Cy7, AntiCd11b-PerCP-Cy5.5, Anti-Cd3e-PerCP-Cy5.5, Anti-Gr-1-PerCP-Cy5.5, Anti-Cd45R/ B220-PerCP-Cy5.5 Anti-Cd4-PerCP-Cy5.5, Anti-Cd8-PerCpCy5.5, Anti-NK1.1-PerCpCy5.5, Anti-Sca1-BV711, Anti-Cd135-APC, Anti-Cd150-BV605, Anti-Siglec1-PE-Cy7 (Biolegend), Anti-Cd34-Alexa Flour 700, Anti-Cd11c-PerCP-Cy5.5 (eBioscience), AntiCd179b-Biotin-V450 Streptavidin, Anti-AA4.1-PE (BD Biosciences), Anti-Axl-APC (R\&D Systems) in D-PBS/2\% (vol/vol) FBS FACS buffer.

\section{Adoptive transfer}

BM from 6-week-old $\mathrm{Bcll1} \mathrm{aF} / \mathrm{F} / \mathrm{mbl}-\mathrm{Cr}{ }^{+} \mathrm{cKO}$ or $\mathrm{Mb}-1-\mathrm{Cre}-Y F P$ reporter mice $(\mathrm{n}=3$ per group) were collected from femurs and transferred via retro-orbital injection into recipient immunocompetent C57/B6 mice lethally irradiated with two doses of $450 \mathrm{rad} 1$ 
hour apart. Mice were kept on an antibiotic diet for 3 weeks to allow for immune reconstitution. Eight weeks post transfer, mice were sacrificed and cells collected from $\mathrm{BM}$ and spleen to investigate reconstitution of cellular subsets.

\section{RNA isolation and RNA-seq}

Total RNA was extracted from FACS sorted Bcl11a cKO BM pDC using TRIzol reagent (Invitrogen). Oligo-dT-primed cDNA was prepared using SuperScript III First-Strand Synthesis System for RT-PCR (Invitrogen). Taq polymerase (New England Biolabs) and a Perkin-Elmer 2700 thermocycler were used to amplify transcripts for the following mouse genes: Bcll1a (F: 5'-GTGGATAAGCCGCCTTCCCCTT-3', R: 5'GGGGACTTCCGTGTTCACTTTC-3'), $\quad$ Pdcal $\quad$ (F: AGGCAAACTCCTGCAACCTG-3', R: 5’- ACCTGCACTGTGCTAGAAGTC-3'), SpiC (F: 5'-ATCCTCACGTCAGAGGCAAC-3', R: 5'-TGTACGGATTGGTGGAAGCC3', Id2 (F: 5'-GGACATCAGCATCCTGTCCTTGC-3' $\quad$ R: $\quad$ 5'GTGTtCTCCTGGTGAAATGGCTGA-3', and $\quad \beta$-actin $\quad$ (F: 5' $^{\prime}$ CAAGGtGtGAtGGtGGGAAT-3'， R: 5'-GGTGtAAAACGCAGCTCAGT-3' For RNA-seq, twelve mice were pooled into three $\mathrm{YFP}^{+}$groups, and total RNA was extracted as above. cDNA was prepared using the Ultra Low kit from Clontech (Mountain View, CA). Library preparation employed the Nextera DNA Library Preparation kit from Illumina (San Diego, CA). cDNA was analyzed by deep sequencing using Illumina sequencing technology. Data were analyzed using a high-throughput next-generation sequencing analysis pipeline: FASTQ files were aligned to the mouse genome ( $\mathrm{mm} 9$, NCBI Build 37) using TopHat $2^{53}$. Gene expression profiles for the individual samples 
were calculated with Cufflinks ${ }^{54}$ as RPKM values. YFP $^{+}$pDC samples were normalized to each control $\mathrm{YFP}^{-}$pDC sample. GO terms identified as significantly different: GO:0006955, GO:0009611, GO:0048584, GO:0006954, GO:0002684, GO:0001775, GO:0009986. Panther terms: BP00148, BP00155, BP00102, BP00120. Gene Set Enrichment Analysis (GSEA) using ordered gene expression levels of Common Lymphoid Progenitor-derived B-pDC and Common Myeloid Progenitor-derived pDC were significantly enriched in both GO terms and Panther-derived gene sets. A randomly selected control GSEA curated set, GSE7831: UNSTIM_VS_INFLUENZA_STIM_ PDC_4H_DN (defined as genes down-regulated in untreated $\mathrm{pDC}$ versus influenza virus infected pDC ${ }^{55}$ showed insignificant enrichment. Normalized enrichment score (NES) and false discovery rate q-values (FDR); FDR $\leq 0.25$ is considered significant ${ }^{56}$.

\section{TLR9 engagement}

Mb1-cre-YFP reporter mice were injected via tail veins with 100ul of PBS containing 50ug of CpG:ODN (n=4) or GpC:ODN control (n=4) (CpG-B no.1826, TCCAT GACG TTCCT GACGTT; control non-CpG-B no.2138, TCCATGAGCTTCCTGAGCTT, Invivogen, USA). At 24 hours, mice were sacrificed and bone marrow and spleens were collected for pDC phenotyping.

\section{Cell co-cultures}

B-pDC $\left(\mathrm{B} 220^{+} \mathrm{Pdca}^{+} \mathrm{Axl}^{+}\right.$Siglec1 $\left.{ }^{+}\right)$and $\mathrm{pDC}\left(\mathrm{B} 220^{+} \mathrm{Pdca}^{+} \mathrm{Axl}^{-}\right.$Siglec1 $\left.{ }^{-}\right)$subsets were sorted on a FACS Aria (BD Biosciences) by and cultured in 96-well round bottom plates with RPMI medium 1640 containing 10\% (vol/vol) FBS, 2 mM L-glutamine, 100 
units/mL penicillin and streptomycin, $1 \mathrm{mM}$ sodium pyruvate, and $10 \mathrm{mM}$ Hepes, and with or without class A CpGs (ODN 1585, InvivoGen) for 24 hours. pDCs were then washed three times to remove residual CpG. Preactivated pDCs $\left(5 \times 10^{3}\right)$ were cultured with CFSE-labeled lymphocytes $\left(2.5 \times 10^{4}\right)$ for $6 \mathrm{~d}$ with 20 units/mL of IL-2.

\section{Enzyme-linked immunosorbent assays (ELISA).}

BM from 6-week-old wildtype C57/BL6 mice was collected from femurs and B-pDC and pDC populations were segregated with a FACS Aria (BD Biosciences). Cells were stimulated with CpG-A (ODN 1585, Invivogen) or CpG-C (ODN 2395, Invivogen) and ELISAs for IFN- $\alpha$ (Invitrogen) or IL-12p40 (BioLegend), respectively, were performed according to manufacturers recommendation.

\section{ChIP followed by ChIP-seq}

ChIP assays for BCL11A were performed and analyzed as described ${ }^{14}$. ChIP-seq data was analyzed by deep sequencing using Illumina sequencing technology as described above.

\section{Data Deposition}

RNA-seq: GSE105827; ChIP-seq: GSE99019

Accession numbers to previously published data sets: GSE52868 (pre-B RNA-seq); GSE55043 (CAL1 ChIP-seq); ENCODE BCL11A ChIP-seq in GM12878 ${ }^{38}$. 
Author contributions: J.D.D. and G.C.I. designed research; J.D.D., C.R., Z.H., and BK.L., performed research; J.D.D., J.L. V.R.I, L.I.E., G.G., and G.C.I., contributed new reagents/analytic tools; J.D.D., C.R., B.-K.L., H.O.T. analyzed data; J.D.D., H.O.T., and G.C.I. wrote the paper.

\section{The authors declare no conflict of interest.}

\section{Acknowledgements}

We thank June V. Harriss for expert assistance in the generation of Bcl11a conditional knockout mice, and Chhaya Das and Maya Ghosh for help in ChIP experiments and cell culture. The CAL1 cell line was kindly provided by Drs. Takahiro Maeda and Boris Reizis. Library preparation and Illumina ChIP- and RNA-seq were performed at the NGS core of the MD Anderson Cancer Center. The Lymphoma Research Foundation Fellowship 300463 (to J.D.D.); NIH grant F32CA110624 and Owens Medical Research Foundation grant (to G.C.I.); NIH grant R01AI104870 (to L.I.R.E.); NIH grant R01CA130075 (to V.R.I.); NIH Grant R01CA31534; Cancer Prevention Research Institute of Texas (CPRIT) Grant RP120348 to the MD Anderson NGS core and CPRIT RP120459 and the Marie Betzner Morrow Centennial Endowment (to H.O.T.) provided support for this work. 


\section{References}

1 Villani, A. C. et al. Single-cell RNA-seq reveals new types of human blood dendritic cells, monocytes, and progenitors. Science 356, doi:10.1126/science.aah4573 (2017).

2 Zhang, H. et al. A distinct subset of plasmacytoid dendritic cells induces activation and differentiation of $\mathrm{B}$ and $\mathrm{T}$ lymphocytes. Proceedings of the National Academy of Sciences of the United States of America 114, 1988-1993, doi:10.1073/pnas.1610630114 (2017).

3 Alcantara-Hernandez, M. et al. High-Dimensional Phenotypic Mapping of Human Dendritic Cells Reveals Interindividual Variation and Tissue Specialization. Immunity 47, 1037-1050.e1036, doi:10.1016/j.immuni.2017.11.001 (2017).

4 Matsui, T. et al. CD2 distinguishes two subsets of human plasmacytoid dendritic cells with distinct phenotype and functions. J Immunol 182, 6815-6823, doi:10.4049/jimmunol.0802008 (2009).

5 Di Domizio, J. \& Cao, W. Fueling Autoimmunity: Type I Interferon in Autoimmune Diseases. Expert review of clinical immunology 9, 10.1586/eci.1512.1106, doi:10.1586/eci.12.106 (2013).

6 Swiecki, M. \& Colonna, M. The multifaceted biology of plasmacytoid dendritic cells. Nat Rev Immunol 15, 471-485, doi:10.1038/nri3865 (2015).

7 Sisirak, V. et al. Genetic evidence for the role of plasmacytoid dendritic cells in systemic lupus erythematosus. J Exp Med 211, 1969-1976, doi:10.1084/jem.20132522 (2014).

8 Ronnblom, L. \& Pascual, V. The innate immune system in SLE: type I interferons and dendritic cells. Lupus 17, 394-399, doi:10.1177/0961203308090020 (2008).

9 Cisse, B. et al. Transcription factor E2-2 is an essential and specific regulator of plasmacytoid dendritic cell development. Cell 135, 37-48 (2008).

10 Ghosh, H. S., Cisse, B., Bunin, A., Lewis, K. L. \& Reizis, B. Continuous expression of the transcription factor e2-2 maintains the cell fate of mature plasmacytoid dendritic cells. Immunity 33, 905-916, doi:S1074-7613(10)00453-X [pii] 10.1016/j.immuni.2010.11.023 (2010).

11 Reizis, B., Bunin, A., Ghosh, H. S., Lewis, K. L. \& Sisirak, V. Plasmacytoid dendritic cells: recent progress and open questions. Annu Rev Immunol 29, 163 183, doi:10.1146/annurev-immunol-031210-101345 (2011).

12 Grajkowska, L. T. et al. Isoform-Specific Expression and Feedback Regulation of E Protein TCF4 Control Dendritic Cell Lineage Specification. Immunity 46, 6577, doi:10.1016/j.immuni.2016.11.006 (2017).

13 Liu, P. et al. Bcl11a is essential for normal lymphoid development. Nat Immunol 4, 525-532 (2003).

14 Ippolito, G. C. et al. Dendritic cell fate is determined by BCL11A. Proceedings of the National Academy of Sciences of the United States of America 111, E9981006, doi:1319228111 [pii] 10.1073/pnas.1319228111 [doi] (2014).

$15 \mathrm{Yu}, \mathrm{Y}$. et al. Bcl11a is essential for lymphoid development and negatively regulates p53. J Exp Med 209, 2467-2483, doi:10.1084/jem.20121846 (2012). 
$16 \mathrm{Wu}, \mathrm{X}$. et al. Bcl11a controls Flt3 expression in early hematopoietic progenitors and is required for $\mathrm{pDC}$ development in vivo. PLoS One 8, e64800, doi:10.1371/journal.pone.0064800 (2013).

17 Pelayo, R. et al. Derivation of 2 categories of plasmacytoid dendritic cells in murine bone marrow. Blood 105, 4407-4415, doi:10.1182/blood-2004-07-2529 (2005).

18 Sathe, P., Vremec, D., Wu, L., Corcoran, L. \& Shortman, K. Convergent differentiation: myeloid and lymphoid pathways to murine plasmacytoid dendritic cells. Blood 121, 11-19, doi:10.1182/blood-2012-02-413336 (2013).

19 Shigematsu, H. et al. Plasmacytoid dendritic cells activate lymphoid-specific genetic programs irrespective of their cellular origin. Immunity 21, 43-53, doi:10.1016/j.immuni.2004.06.011 S1074761304001712 [pii] (2004).

20 Wang, Y. H. \& Liu, Y. J. Mysterious origin of plasmacytoid dendritic cell precursors. Immunity 21, 1-2, doi:10.1016/j.immuni.2004.07.003

S107476130400175X [pii] (2004).

21 Yang, G. X. et al. Plasmacytoid dendritic cells of different origins have distinct characteristics and function: studies of lymphoid progenitors versus myeloid progenitors. J Immunol 175, $7281-7287$ (2005).

22 Mellor, A. L. et al. Cutting edge: $\mathrm{CpG}$ oligonucleotides induce splenic CD19+ dendritic cells to acquire potent indoleamine 2,3-dioxygenase-dependent $\mathrm{T}$ cell regulatory functions via IFN Type 1 signaling. J Immunol 175, 5601-5605 (2005).

23 Munn, D. H. et al. Expression of indoleamine 2,3-dioxygenase by plasmacytoid dendritic cells in tumor-draining lymph nodes. J Clin Invest 114, 280-290, doi:10.1172/jci21583 (2004).

24 Hobeika, E. et al. Testing gene function early in the B cell lineage in mb1-cre mice. Proceedings of the National Academy of Sciences of the United States of America 103, 13789-13794, doi:10.1073/pnas.0605944103 (2006).

25 Sakaguchi, N., Kashiwamura, S., Kimoto, M., Thalmann, P. \& Melchers, F. B lymphocyte lineage-restricted expression of mb-1, a gene with CD3-like structural properties. The EMBO journal 7, 3457-3464 (1988).

26 Inlay, M. A. et al. Ly6d marks the earliest stage of B-cell specification and identifies the branchpoint between B-cell and T-cell development. Genes \& Development 23, 2376-2381, doi:10.1101/gad.1836009 (2009).

27 Huang, D. W., Sherman, B. T. \& Lempicki, R. A. Bioinformatics enrichment tools: paths toward the comprehensive functional analysis of large gene lists. Nucleic Acids Res 37, 1-13, doi:10.1093/nar/gkn923 (2009).

28 Thomas, P. D. et al. PANTHER: a library of protein families and subfamilies indexed by function. Genome research 13, 2129-2141, doi:10.1101/gr.772403 (2003).

29 Liu, G. J. et al. Pax5 loss imposes a reversible differentiation block in Bprogenitor acute lymphoblastic leukemia. Genes Dev 28, 1337-1350, doi:10.1101/gad.240416.114 (2014).

30 Greenwald, R. J., Freeman, G. J. \& Sharpe, A. H. The B7 family revisited. Annu Rev Immunol 23, 515-548, doi:10.1146/annurev.immunol.23.021704.115611 (2005). 
31 Seth, S. et al. CCR7 Essentially Contributes to the Homing of Plasmacytoid Dendritic Cells to Lymph Nodes under Steady-State As Well As Inflammatory Conditions. The Journal of Immunology 186, 3364-3372, doi:10.4049/jimmunol.1002598 (2011).

32 Riol-Blanco, L. et al. The Chemokine Receptor CCR7 Activates in Dendritic Cells Two Signaling Modules That Independently Regulate Chemotaxis and Migratory Speed. The Journal of Immunology 174, 4070-4080, doi:10.4049/jimmunol.174.7.4070 (2005).

33 Penna, G., Vulcano, M., Sozzani, S. \& Adorini, L. Differential migration behavior and chemokine production by myeloid and plasmacytoid dendritic cells. Human immunology 63, 1164-1171 (2002).

34 Cavanagh, L. L. \& Von Andrian, U. H. Travellers in many guises: The origins and destinations of dendritic cells. Immunol Cell Biol 80, 448-462 (2002).

35 Shay, T. \& Kang, J. Immunological Genome project and systems immunology. Trends in immunology 34, 602-609, doi:10.1016/j.it.2013.03.004 (2013).

36 Liu, Y.-J. IPC: Professional Type 1 Interferon-Producing Cells and Plasmacytoid Dendritic Cell Precursors. Annual Review of Immunology 23, 275-306, doi:10.1146/annurev.immunol.23.021704.115633 (2005).

37 Lood, C. et al. Clq inhibits immune complex-induced interferon-alpha production in plasmacytoid dendritic cells: a novel link between $\mathrm{Clq}$ deficiency and systemic lupus erythematosus pathogenesis. Arthritis and rheumatism 60, 3081-3090, doi:10.1002/art.24852 (2009).

38 ENCODE. The ENCODE (ENCyclopedia Of DNA Elements) Project. Science 306, 636-640, doi:10.1126/science.1105136 (2004).

39 Karrich, J. J. et al. The transcription factor Spi-B regulates human plasmacytoid dendritic cell survival through direct induction of the antiapoptotic gene BCL2A1. Vol. 119 (2012).

40 Carmona-Sáez, P. et al. Metagene projection characterizes GEN2.2 and CAL-1 as relevant human plasmacytoid dendritic cell models. Bioinformatics (Oxford, England) 33, 3691-3695, doi:10.1093/bioinformatics/btx502 (2017).

41 Maeda, T. et al. A novel plasmacytoid dendritic cell line, CAL-1, established from a patient with blastic natural killer cell lymphoma. International journal of hematology 81, 148-154 (2005).

42 Ceribelli, M. et al. A Druggable TCF4- and BRD4-Dependent Transcriptional Network Sustains Malignancy in Blastic Plasmacytoid Dendritic Cell Neoplasm. Cancer Cell 30, 764-778, doi:10.1016/j.ccell.2016.10.002 (2016).

43 Bjorck, P. \& Kincade, P. W. CD19+ pro-B cells can give rise to dendritic cells in vitro. J Immunol 161, 5795-5799 (1998).

44 Izon, D. et al. A common pathway for dendritic cell and early B cell development. J Immunol 167, 1387-1392 (2001).

45 Ghosh, H. S. et al. ETO family protein Mtg16 regulates the balance of dendritic cell subsets by repressing Id2. $J$ Exp Med 211, 1623-1635, doi:10.1084/jem.20132121 (2014).

46 Sasaki, I. et al. Spi-B is critical for plasmacytoid dendritic cell function and development. Blood 120, 4733-4743, doi:10.1182/blood-2012-06-436527 (2012). 
47 Zhu, X., Schweitzer, B. L., Romer, E. J., Sulentic, C. E. \& DeKoter, R. P. Transgenic expression of Spi-C impairs B-cell development and function by affecting genes associated with BCR signaling. Eur J Immunol 38, 2587-2599, doi:10.1002/eji.200838323 (2008).

48 Li, S. K., Solomon, L. A., Fulkerson, P. C. \& DeKoter, R. P. Identification of a negative regulatory role for spi-C in the murine B cell lineage. J Immunol 194, 3798-3807, doi:10.4049/jimmunol.1402432 (2015).

49 Braig, F. et al. Resistance to anti-CD19/CD3 BiTE in acute lymphoblastic leukemia may be mediated by disrupted CD19 membrane trafficking. Blood 129, 100-104, doi:10.1182/blood-2016-05-718395 (2017).

50 Heidkamp, G. F. et al. Human lymphoid organ dendritic cell identity is predominantly dictated by ontogeny, not tissue microenvironment. Science Immunology 1, doi:10.1126/sciimmunol.aai7677 (2016).

51 Li, S., Wu, J., Zhu, S., Liu, Y. J. \& Chen, J. Disease-Associated Plasmacytoid Dendritic Cells. Front Immunol 8, 1268, doi:10.3389/fimmu.2017.01268 (2017).

52 Affandi, A. J., Carvalheiro, T., Radstake, T. \& Marut, W. Dendritic cells in systemic sclerosis: Advances from human and mice studies. Immunol Lett, doi:10.1016/j.imlet.2017.11.003 (2017).

53 Kim, D. et al. TopHat2: accurate alignment of transcriptomes in the presence of insertions, deletions and gene fusions. Genome Biol 14, R36, doi:10.1186/gb2013-14-4-r36 (2013).

54 Trapnell, C. et al. Differential analysis of gene regulation at transcript resolution with RNA-seq. Nature biotechnology 31, 46-53, doi:10.1038/nbt.2450 (2013).

55 Iparraguirre, A. et al. Two distinct activation states of plasmacytoid dendritic cells induced by influenza virus and CpG 1826 oligonucleotide. Journal of leukocyte biology 83, 610-620, doi:10.1189/jlb.0807511 (2008).

56 Mootha, V. K. et al. PGC-1alpha-responsive genes involved in oxidative phosphorylation are coordinately downregulated in human diabetes. Nat Genet 34, 267-273, doi:10.1038/ng1180 (2003). 


\section{Figure Legends}

Figure 1. Mb1-Cre deletion of Bcl11a identifies a CLP-derived subset of pDCs.

(a) $\mathrm{B} 220^{+} \mathrm{Pdcal}^{+} \mathrm{Cd}_{11 \mathrm{~b}^{-}} \mathrm{pDC}$ are consistently reduced in $\mathrm{Bcllla}^{\mathrm{F} / F} \mathrm{mbl-Cre}$ mice by $\sim 25 \%(\mathrm{p}=0.0004)$ relative to littermate controls. $\mathrm{B} 220^{+} \mathrm{B}$ cell numbers are reduced by greater than 50\% $(\mathrm{p}<0.0001)$ (Representative plots and summary table in Fig. S2). (b) B cell numbers after adoptive transfer of bone marrow (BM) from 6-week-old

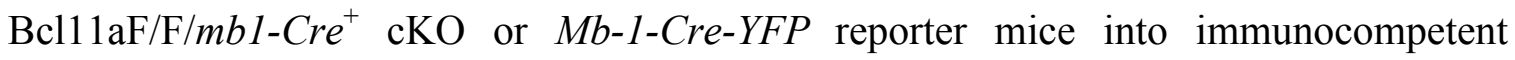
irradiated recipient $\mathrm{C57} / \mathrm{B} 6$ mice. (c) Reduction of $\mathrm{pDC}$ in the $\mathrm{BM}$ of recipient mice was significant only in the $\mathrm{YFP}^{+}$set $(\mathrm{p}=0.007)$. (d) Percentage of $\mathrm{YFP}^{+} \mathrm{pDC}$ is significantly higher in the spleen compared to the BM (p=0.011). (e) Both Bcl11aF/F/mb1-Cre $e^{+}$and Mb-1-Cre-YFP adoptively transferred recipient mice reconstituted other splenic cell types in normal numbers, including $\mathrm{BM}$ macrophages $\left(\mathrm{Cd} 11 \mathrm{~b}^{+} \mathrm{F} 4 / 80^{+}\right)$, granulocytes $(\mathrm{Gr}$ $\left.1^{+} \mathrm{Cd} 11 \mathrm{~b}^{+}\right)$and splenic cDCs $\left(\mathrm{Cd} 11 \mathrm{c}^{+} \mathrm{Cd} 11 \mathrm{~b}^{+} \mathrm{B} 220^{-}\right)$. Total $\mathrm{T}$ cells $\left(\mathrm{Cd} 3^{+} \mathrm{B} 220^{-}\right)$as well as $\mathrm{Cd}^{+}$and $\mathrm{Cd} 8^{+}$subsets were significantly increased in number in proportion to $\mathrm{B} / \mathrm{pDC}$ cell loss. YFP expression in each of these lineages was rare $(<1 \%)$. Students T-test was used for all statistical comparisons.

Figure 2. Transcriptional analysis identifies two populations of pDC in mice: myeloid-derived classical pDC and CLP-derived B-pDC.

(a) Bone marrow pDC (B220+Pdca1+Cd11cintCd11b-) were sorted based on expression of YFP. Four mice were pooled for each isolated RNA sample, for a total of three pDC and three B-pDC groups from 12 mice. (b) RNA-seq was performed for gene expression analysis of pDC vs B-pDC and 220/23,946 genes ( $1 \%$, left) were significantly 
differentially expressed $\left(q\right.$ value $<0.05$, right heatmap, $\log _{2}$ expression difference displayed). (c) Gene Set Enrichment Analysis (GSEA). Normalized enrichment score (NES) and false discovery rate q-values (FDR); FDR $\leq 0.25$ is considered significant ${ }^{56}$.

(d) Scatter plot comparisons of all genes with Reads Per Kilobase of transcript, per Million mapped reads $(\mathrm{RPKM})>1$. Correlations of $\mathrm{pDC}$ vs $\mathrm{B}-\mathrm{pDC}\left(\mathrm{R}^{2}\right.$ value $\left.=0.8959\right)$, $B$ cell vs. $p D C R^{2}$ value $\left.=0.4145\right)$ and $B$ cell vs. $B-p D C\left(R^{2}\right.$ value $\left.=0.404\right)$ are indicated (e) A selected subset of genes from RNA-seq of $\mathrm{pDC}$ and B-pDC is shown. Genes with similar expression among pDC subsets included the pDC hallmark genes Tcf4, Pdca1, and Cd11c. Those with differential expression included the prototypic B cell genes Cd19,VpreB1, and VpreB3, Cd83 and Cd86. Ax1, Siglec1, Cd2, Cd81, Lyz1, Ccr7, were expressed higher in the B-pDC compartment, and B cell specific factors Tcf3, Foxp1, and Pax5 were only expressed in the BM-derived mouse pre-B cells $\left(\mathrm{B} 220^{+} \operatorname{IgM}^{-} \mathrm{Kit}^{-} \mathrm{Cd} 25^{+}\right)^{29}$.

Figure 3. CLP-derived B-pDC share cellular and functional phenotype with human $\mathrm{AXL}^{+} \mathbf{D C}$ subset.

(a) Bone marrow from $\mathrm{Mb}$-1-Cre-YFP reporter mice analyzed for surface expression of Cd19 and MHCII expression. A high percentage of $\mathrm{YFP}^{+} \mathrm{pDC}$ were $\mathrm{Cd}_{19}{ }^{+}$and showed higher expression of $\mathrm{MHC}$ class II in the $\mathrm{YFP}^{+}$fraction as compared to the $\mathrm{YFP}^{-}$fraction. (b) Bone marrow from $M b-1-C r e-Y F P$ reporter mice analyzed for surface expression of Axl, Siglec1, Cd19, and Cd86. $\sim 20 \%$ of total pDC expressed these markers and were $\mathrm{YFP}^{+}$. (c) Mice injected with 50ug/ml (100ul) of $\mathrm{CpG}$ :ODN or GpC:ODN controls analyzed for activation markers showed increased splenic pDC numbers overall, but 3fold higher expansion of $\mathrm{YFP}^{+} \mathrm{B}-\mathrm{pDC}$. (d) $\mathrm{CpG}$ :ODN injected mice expanded pDC with 
increased levels of surface activation indicators, Cd86, Cd83, and MHCII in both $\mathrm{YFP}^{-}$ and $\mathrm{YFP}^{+} \mathrm{pDC}$ (red boxes). Note that $\mathrm{YFP}^{+} \mathrm{pDC}$ expanded more robustly and expressed higher levels of $\mathrm{Cd} 86$, MHCII and Cd83 (green $=\mathrm{YFP}^{+}$, black=YFP${ }^{-}$) (e) In vitro TLR9 engagement of $\mathrm{B}-\mathrm{pDC}$ or $\mathrm{pDC}$ for ELISA against IFN- $\alpha$ or (f) IL-12p40. $(* * * * p<0.0001)$. (g) $\mathrm{CD}^{+} \mathrm{T}$ cell expansion, by CFSE dilution, of CFSE-labeled murine lymphocytes $\left(2.5 \times 10^{4}\right)$ cultured alone or with $\mathrm{CpG}$ :ODN activated B-pDCs or pDCs $\left(5 \times 10^{3}\right)$ in triplicate for $6 \mathrm{~d}$. Representative plots shown. (h) The percentage of CFSEnegative $\mathrm{Cd}^{+} \mathrm{T}$ cells in co-cultures were significantly higher in B-pDC compared to $\mathrm{pDC}(* p=0.02)$.

Figure 4. ChIP-seq analysis of genome-wide BCL11A target binding in multiple human cell lines underscores an evolutionarily conserved transcriptional hierarchy distinguishing B-pDC and B cells in both humans and mice.

ChIP-seq for BCL11A was performed in the human pre-B cell line NALM6 (green) and the human Burkitt's lymphoma line RAJI (black) and was compared to ChIP-seq acquired in the human pDC model cell-line CAL1 (blue) and the ENCODE consortium acquired ChIP-seq of the human B lymphoblastoid cell line GM12878 (red, all peak scores $\geq 10$ ). (a) Overlap of BCL11A target genes between the four cell lines. A target gene was defined by a binding site occurring within $50 \mathrm{~kb}$ upstream through the intron of that gene. Analysis of the false discovery rate and associated q-values were performed using Benjamini-Hochberg statistics. (b) Selected overlapping and differentially bound targets in $\mathrm{B}$ and $\mathrm{pDC}$ lines (peak scores $\geq 10$ ). 
Figure 5. A bipartite model of pDC development.

Following a split from multipotent progenitors (MPP), common dendritic progenitors (CDP) progress to classical pDCs via constitutive expression of Tcf4 and Bcl11a through a positive feedback loop (unshaded and previously established ${ }^{9,10,14,45}$ ). A second lineage, B-pDC can be generated from the CLP via an incompletely defined mechanism but which requires Bcl11a. B-pDC display Cd19, Axl, and Siglec1 on their surface (shaded area, established herewithin). 
A

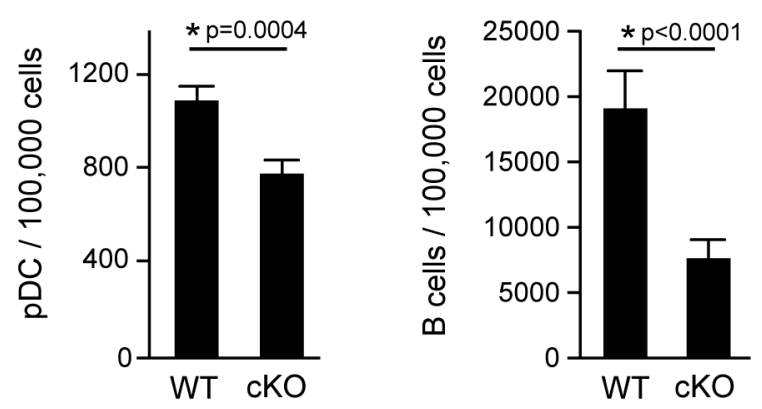

\section{B-E: Adoptive Transfer Data \\ $\square$ YFP $^{+}$ \\ $\square$ YFP $^{-}$}

B

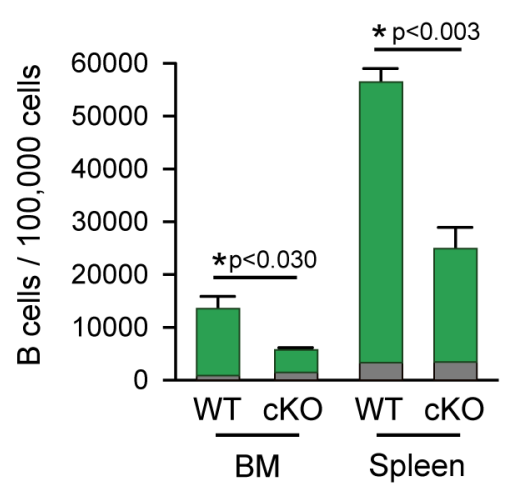

C

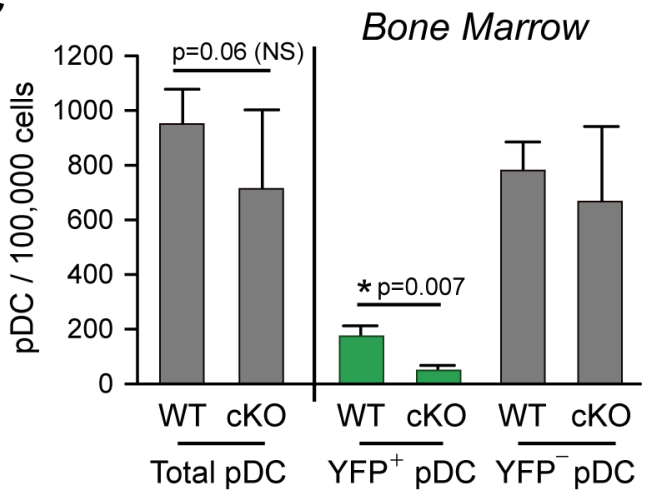

D

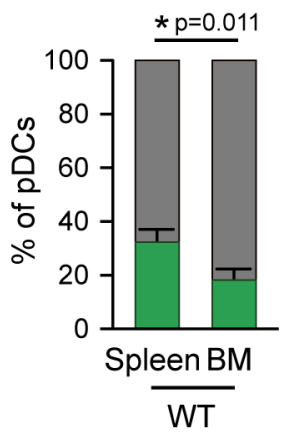

$E$

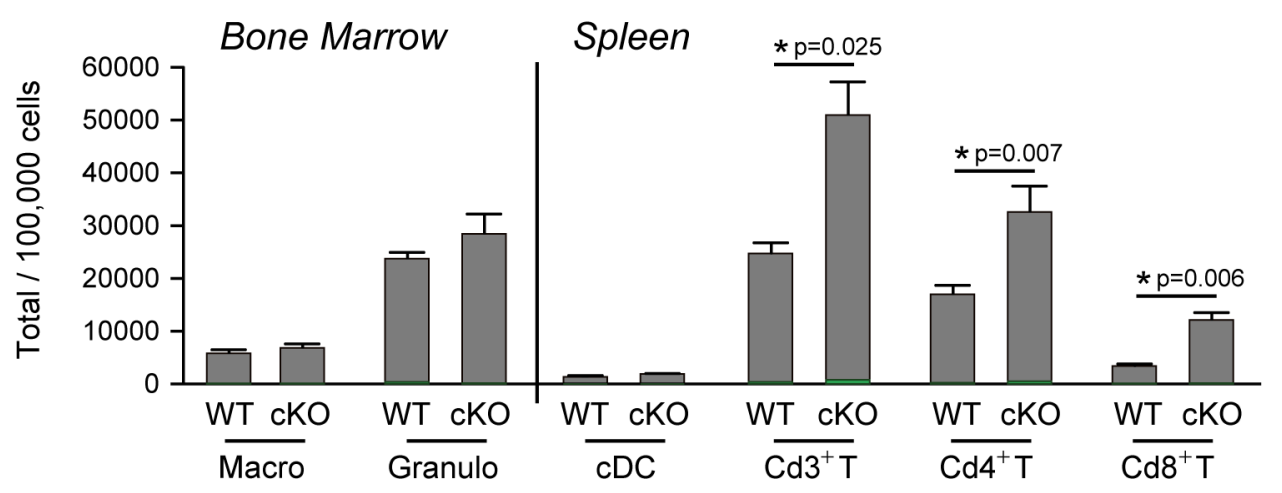

Figure 1 
bioRxiv preprint doi: https://doi.org/10.1101/310680; this version posted April 30, 2018. The copyright holder for this preprint (which was not certified by peer review) is the author/funder, who has granted bioRxiv a license to display the preprint in perpetuity. It is made available under aCC-BY-NC-ND 4.0 International license.

A
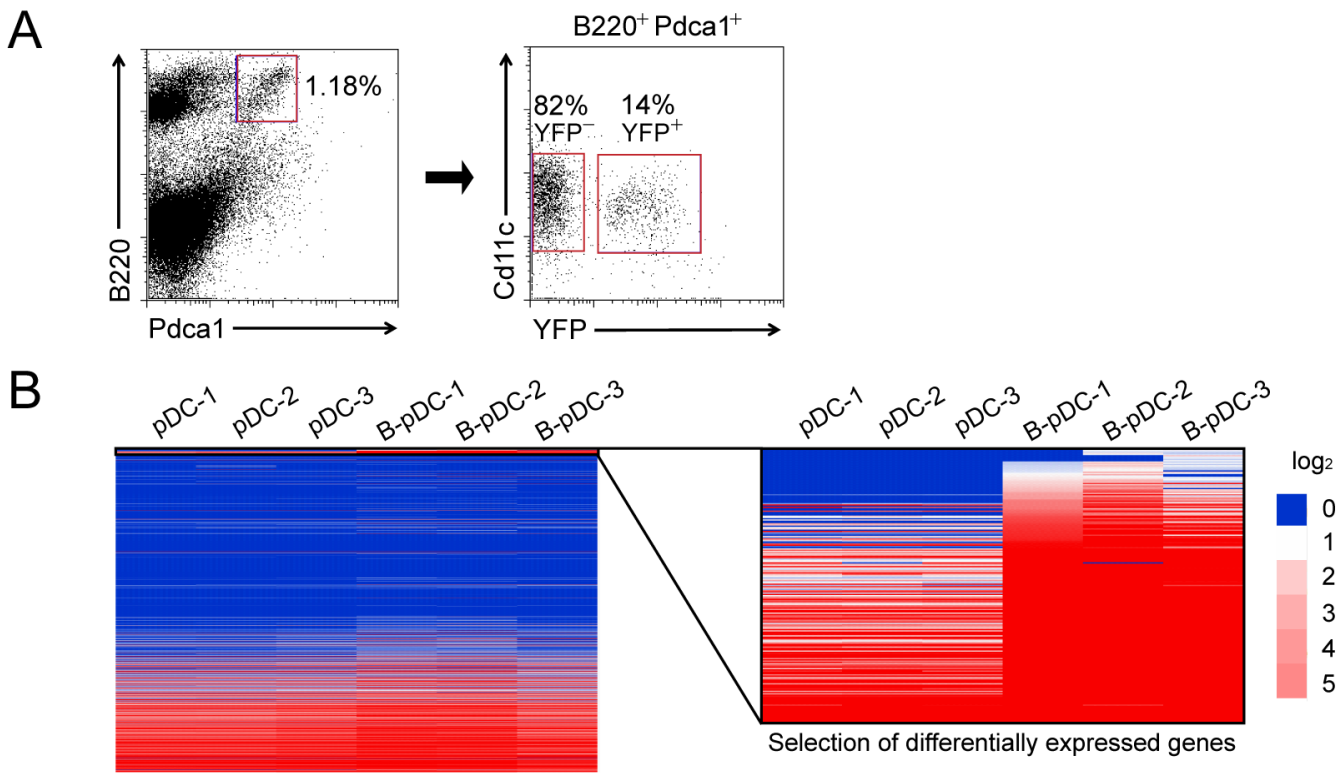

All Gene Expression (23,946 genes)
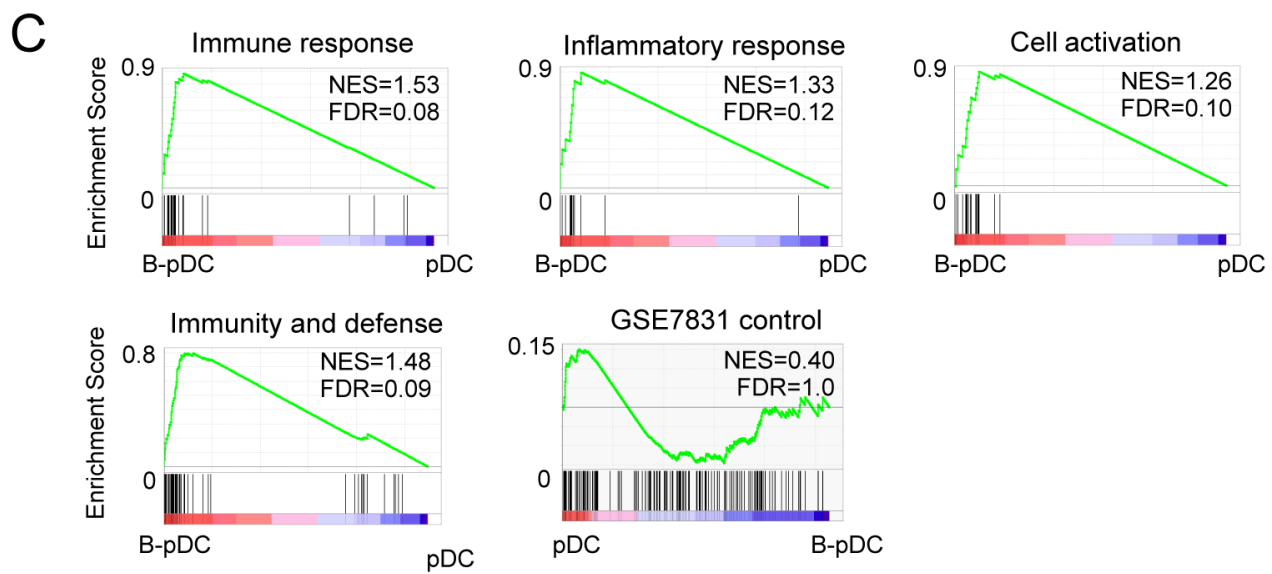

D
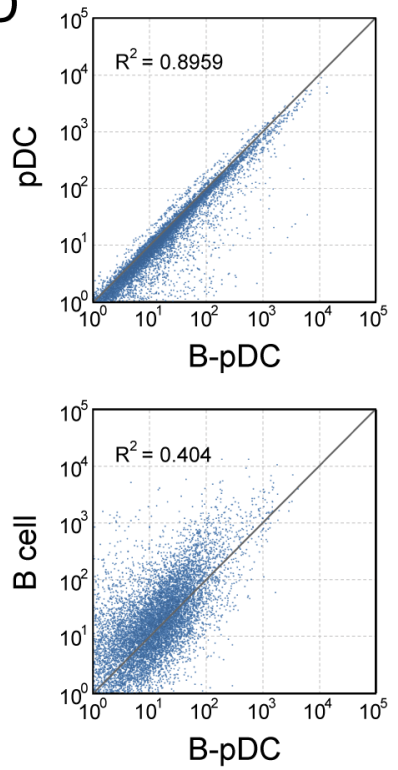

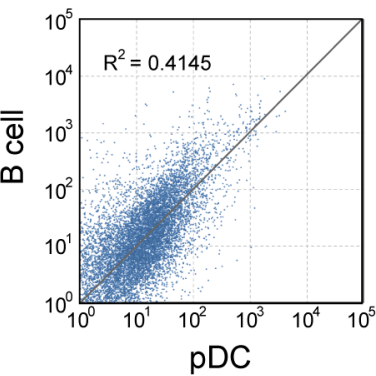

$E$
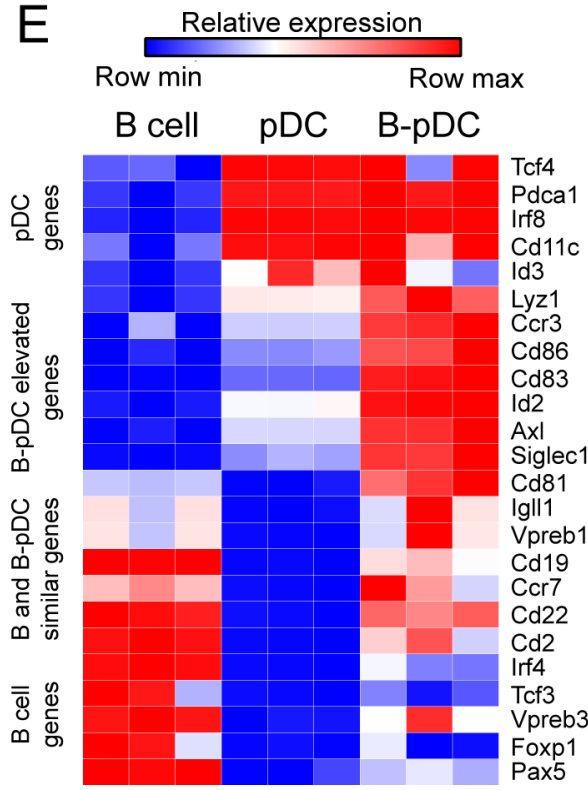
A

B
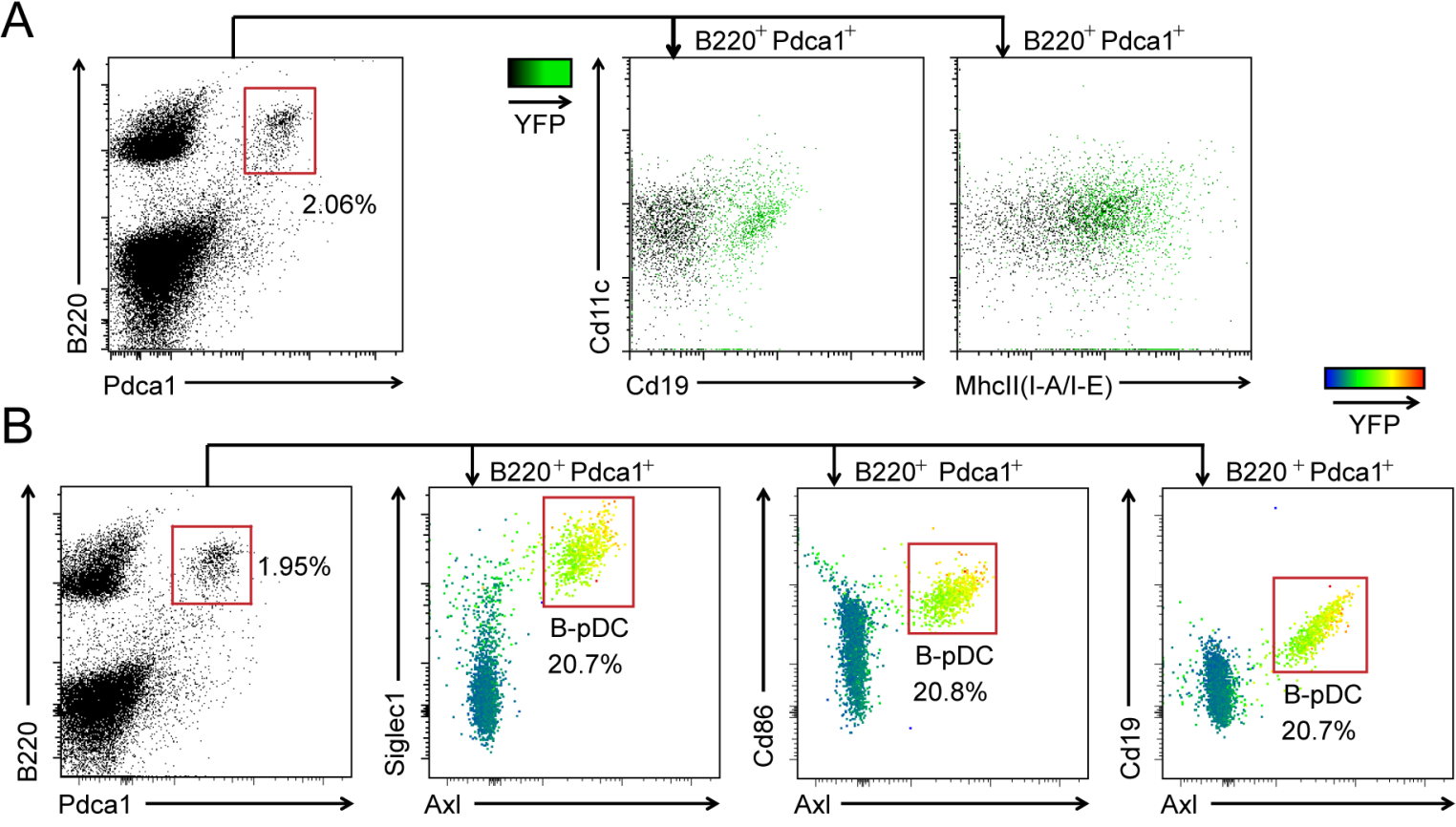

C

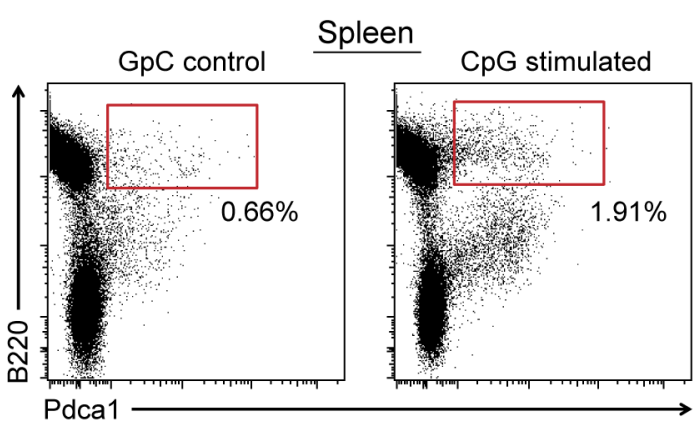

\begin{tabular}{l|c|c}
\hline & YFP $^{-}$ & YFP $^{+}$ \\
\hline \hline GpC control / 100K cells & 1,151 & 1,311 \\
CpG stimulated / 100K cells & 3,284 & 9,113 \\
\hline
\end{tabular}

D

B220 ${ }^{+} \mathrm{Pdca}^{+} \mathrm{Cd} 11 \mathrm{c}^{\text {int }}$ Splenocytes
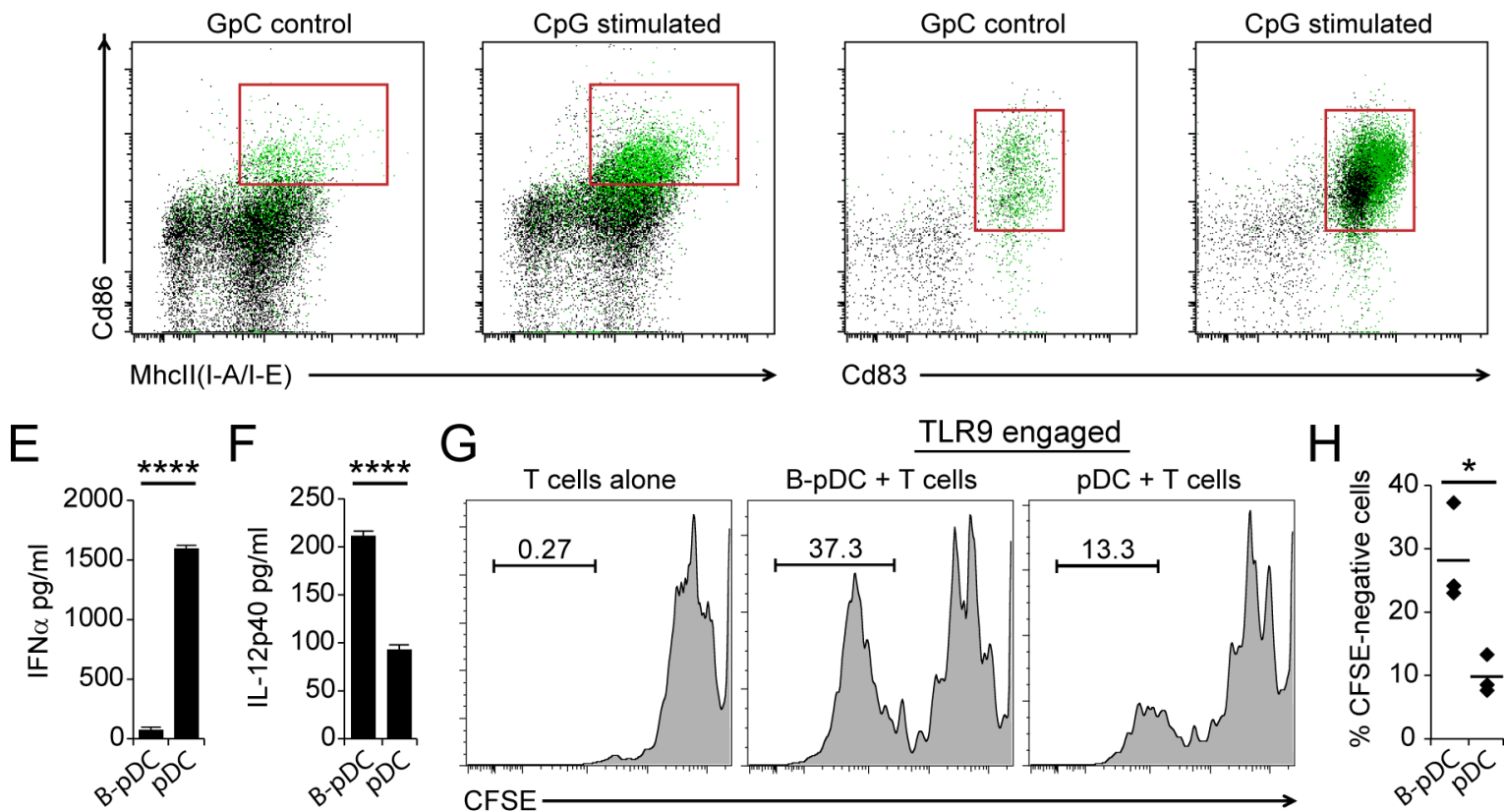

G

TLR9 engaged

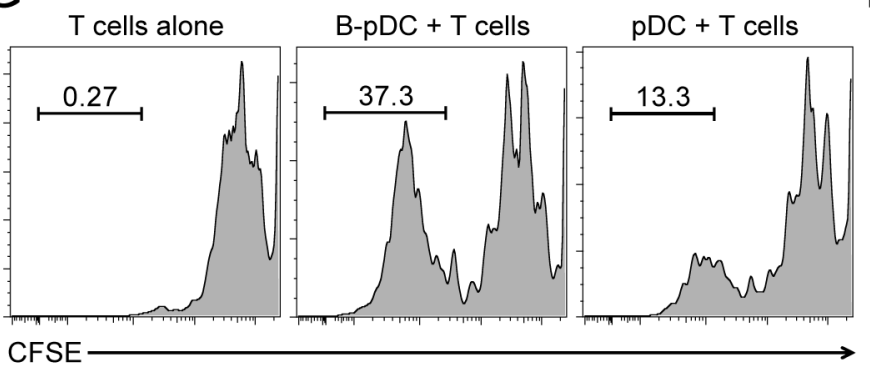

$\mathrm{H}$

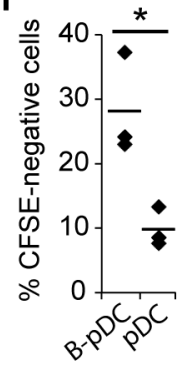


A

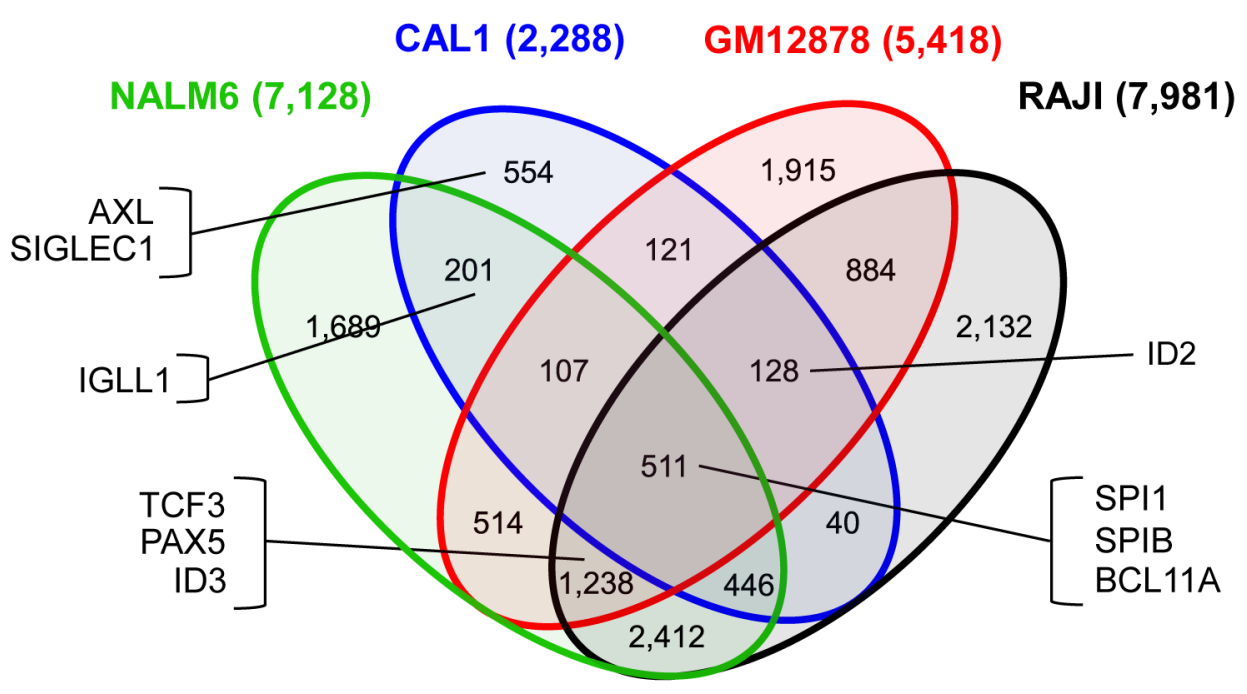

B

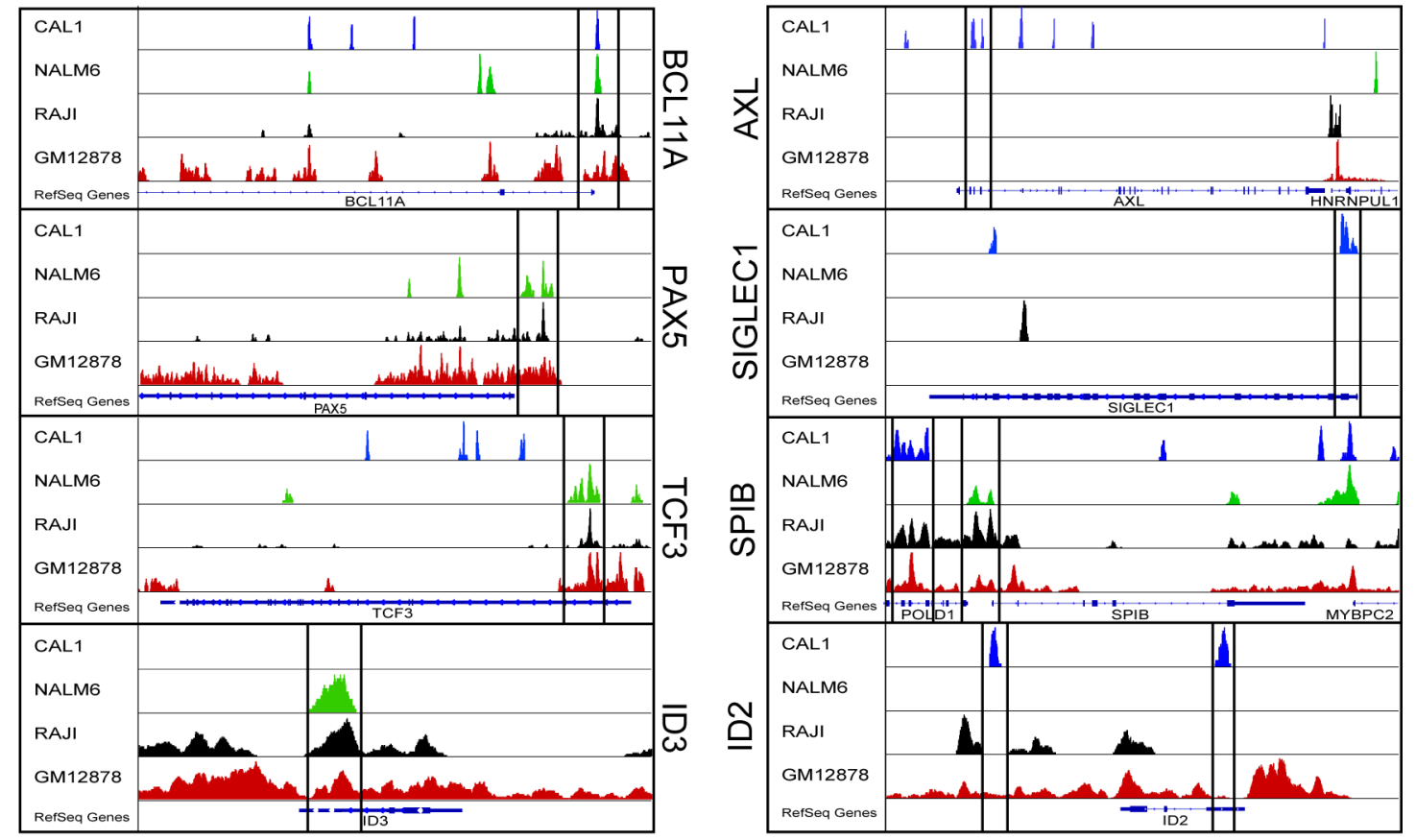

IGLL1

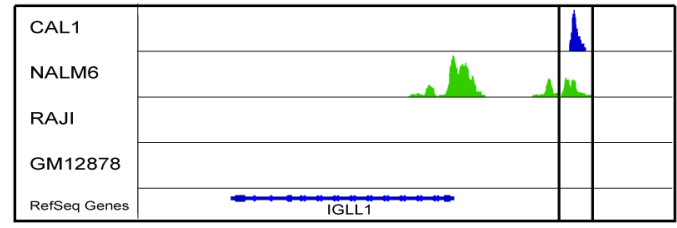

Figure 4 
bioRxiv preprint doi: https://doi.org/10.1101/310680; this version posted April 30, 2018. The copyright holder for this preprint (which was not certified by peer review) is the author/funder, who has granted bioRxiv a license to display the preprint in perpetuity. It is made available under aCC-BY-NC-ND 4.0 International license.

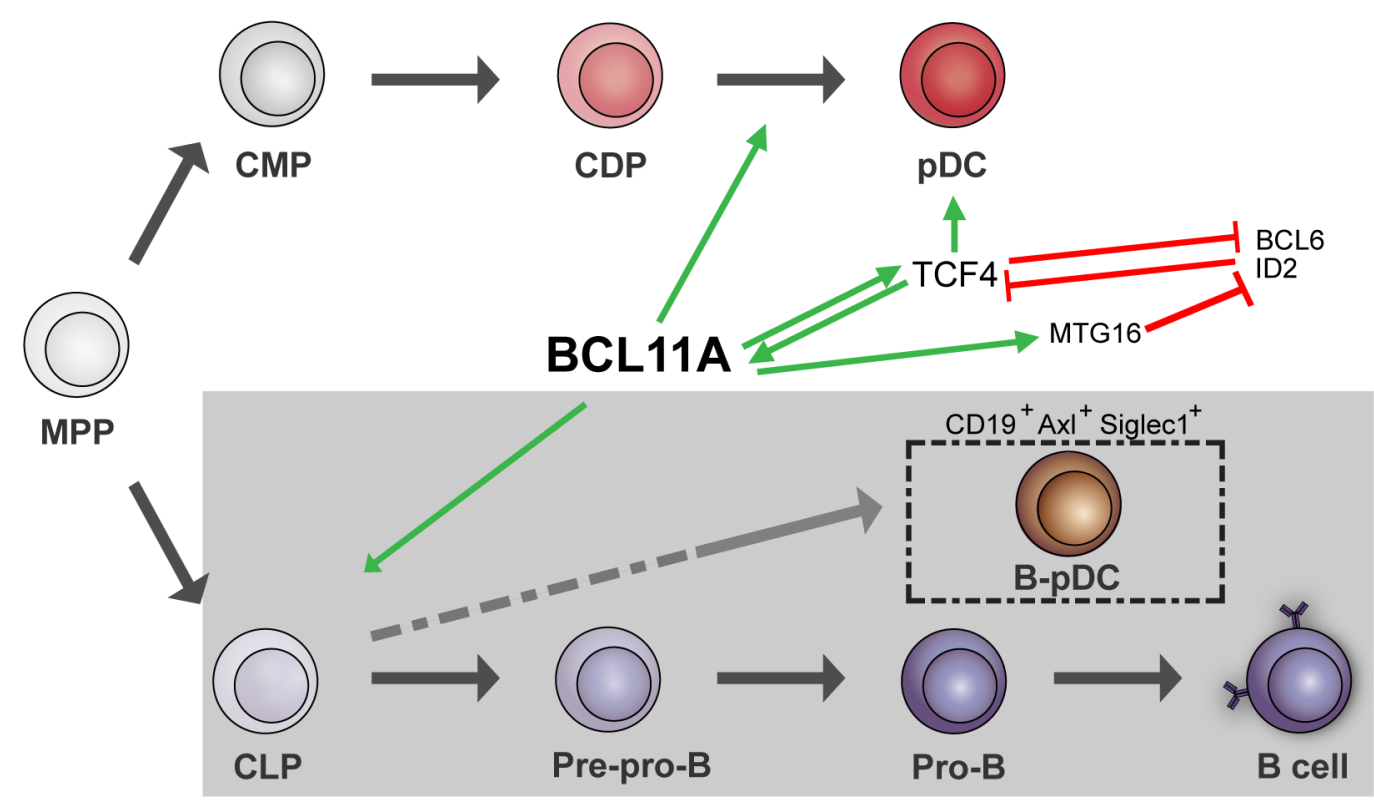

Figure 5 


\section{SUPPLEMENTAL MATERIAL}

\section{Lymphoid origin of a lineage of intrinsically activated plasmacytoid dendritic cell in mice and humans}

Joseph D. Dekker, Catherine Rhee, Zicheng Hu, Bum-Kyu Lee, Jiwon Lee, Vishwanath R. Iyer, Lauren I. R. Ehrlich, George Georgiou, Haley O. Tucker, and Gregory C. Ippolito

Figures S1-S6. 
bioRxiv preprint doi: https://doi.org/10.1101/310680; this version posted April 30, 2018. The copyright holder for this preprint (which was not certified by peer review) is the author/funder, who has granted bioRxiv a license to display the preprint in perpetuity. It is made available under aCC-BY-NC-ND 4.0 International license.

\section{A Early Progenitors}

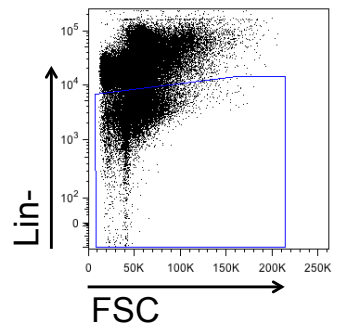

Lineage B220, Cd19, Cd3, Cd4, Cd8, Cd11b,Cd11c, Ly6G, Ter119, Nk1.1

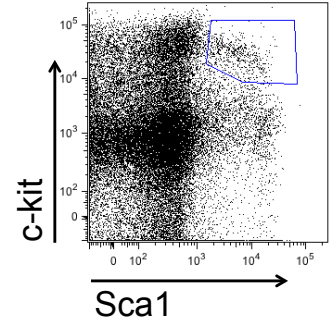

Lin-
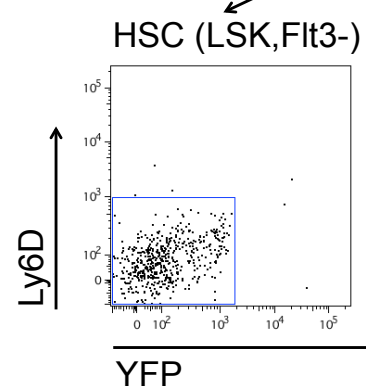

LSK
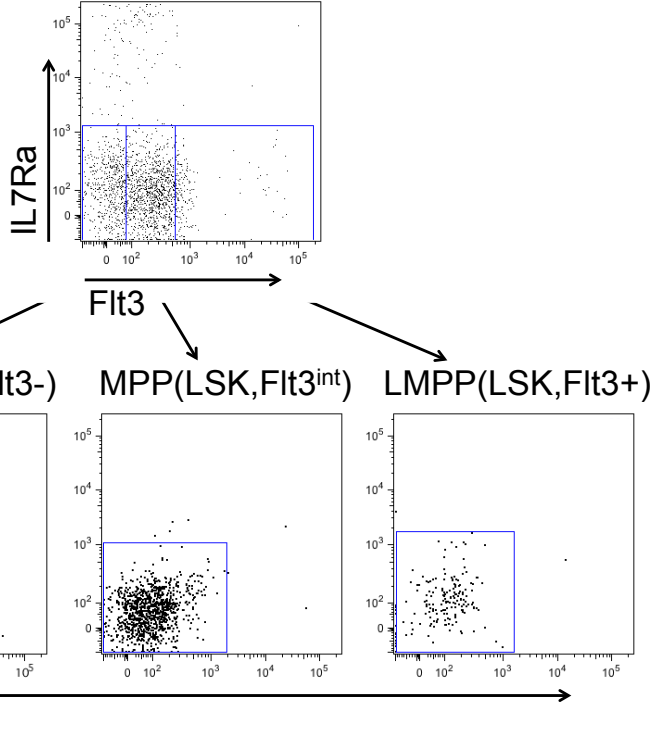

\section{B Myeloid-Dendritic Progenitors}

Lin-, IL7Ra-

Flt3+, c-kithi,

Sca1-

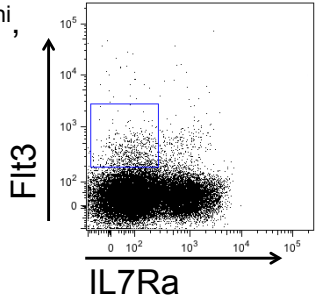

Lin-IL7Ra-Flt3+

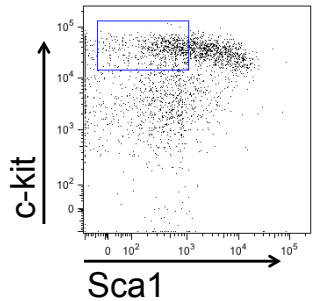

MDP

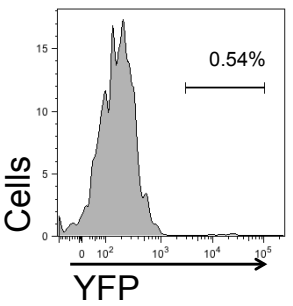

\section{Common Dendritic Progenitor}

Lin-, IL7Ra-,

Flt3+, Cd115+,

c-kitow,

Sca1-

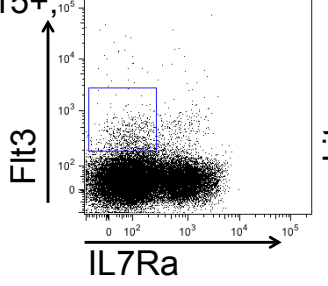

Lin-IL7Ra-FIt3+

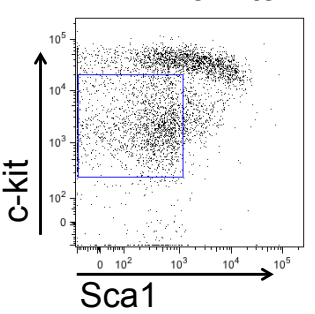

Lin-IL7Ra- Flt3+ c-kitowSca1-
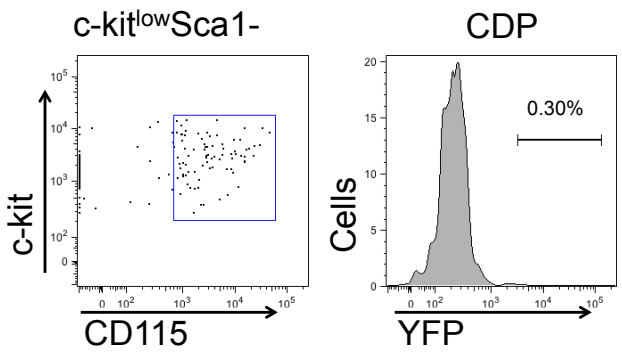

\section{Common Lymphoid Progenitors}

Lin-, IL7Ra+

Flt3+,c-kitto, Sca1 ${ }^{10}$

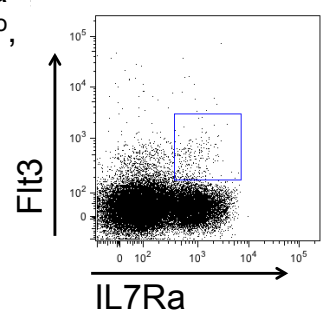

\begin{abstract}
Lin-
\end{abstract}

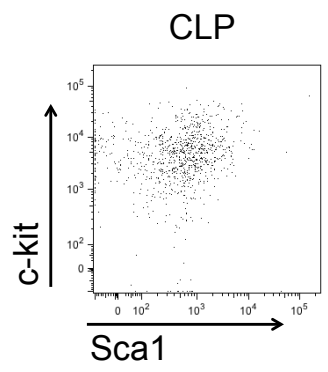

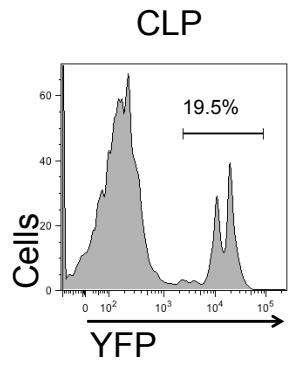

Supplemental Figure 1. Progenitor population analysis for mb1-cre driven YFP expression.

We analyzed YFP expression in BM progenitors to determine when and where mb1-Cre is active (representative plots shown). (a) Lineage negative cells were analyzed to examine LSK Hematopoietic progenitor (Lin-, Sca-1+, c-Kit+), MPP (LSK, Flt $3^{\text {int }}$ ), and LMPP (LSK, Flt3 ${ }^{\text {hi }}$ ), populations. Virtually all cells were YFP-. (b) Myeloid Dendritic Progenitors

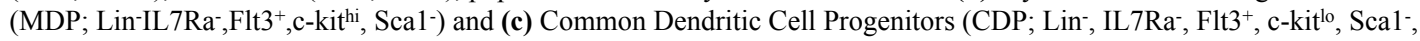
$\mathrm{Cd}_{115^{+}}$) were also negative for YFP expression, while (d) Common Lymphoid Progenitors (CLP; Lin', IL7Ra ${ }^{+}$, Flt3 ${ }^{+}$, c$\mathrm{kit}^{\mathrm{lo}}, \mathrm{Sca}^{\mathrm{lo}}$ ) contained $\mathrm{YFP}^{+}$cells. 
bioRxiv preprint doi: https://doi.org/10.1101/310680; this version posted April 30, 2018. The copyright holder for this preprint (which was not certified by peer review) is the author/funder, who has granted bioRxiv a license to display the preprint in perpetuity. It is made available under aCC-BY-NC-ND 4.0 International license.
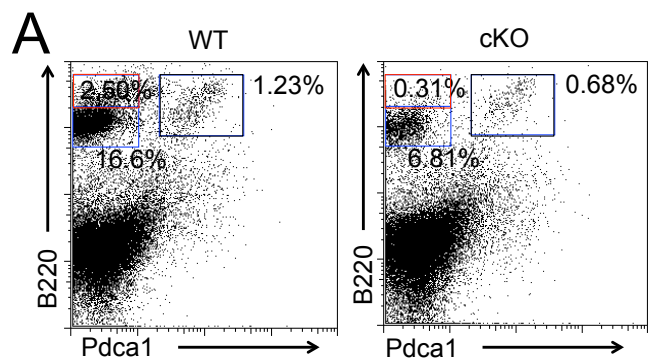

Recirculating B cells

Immature B cells

$\mathrm{pDC}$

\begin{tabular}{|c|c|c|c|}
\hline $\begin{array}{c}\text { Cell Typel } \\
\text { 100K }\end{array}$ & WT & cKO & P-value \\
\hline B cells & $19,100 \pm 2879$ & $7,633 \pm 1426$ & $<0.0001$ \\
\hline pDC & $1,086 \pm 65$ & $766 \pm 63$ & 0.0004 \\
\hline
\end{tabular}
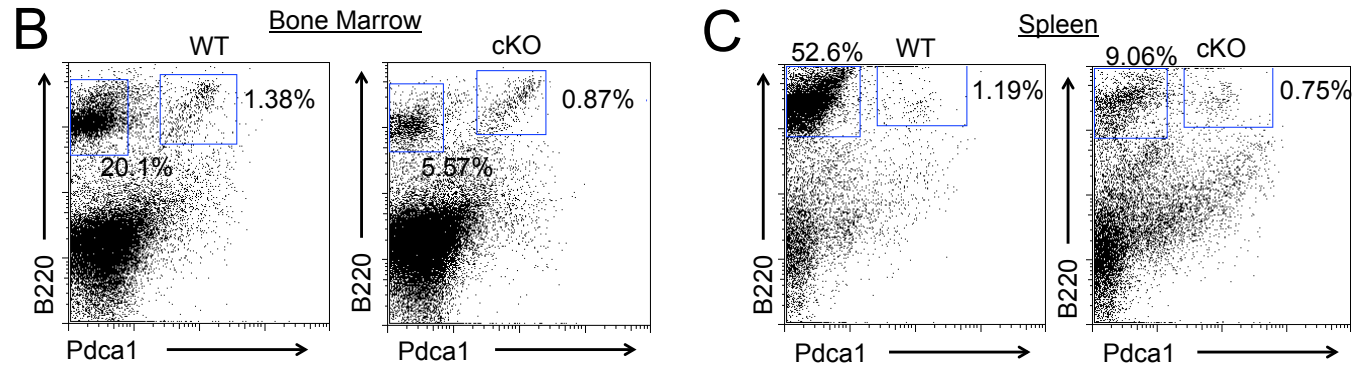

Supplemental Figure 2. Representative FACS plots of cKO and adoptive transfer data.

(a) $\mathrm{B} 220^{+} \mathrm{Pdca} 1^{+} \mathrm{Cd} 11 \mathrm{~b}^{-} \mathrm{pDC}$ were consistently reduced in the $\mathrm{cKO}$ relative to littermate controls. As would be expected if $\mathrm{pDC}$ were partially generated from the CLP, $\mathrm{pDC}$ were reduced by $14-30 \%$ in the $\mathrm{Bc} 111 \mathrm{aF} / \mathrm{F} / \mathrm{mb} 1-\mathrm{Cre}+$ $\mathrm{cKO}(\mathrm{p}=0.0009)$, while $\mathrm{B} 220^{+}$Pdca1- B-cell numbers were reduced by greater than $50 \%$ including loss of most $\mathrm{B} 220^{\mathrm{hi}}$ recirculating $\mathrm{B}$ cells which served as an indirect gauge of mb1-Cre deletion efficiency in vivo $(\mathrm{p}<0.0001)$ (Representative plots and summary table shown, $\mathrm{n}=6$ ). (b) Representative FACS plots of $\mathrm{pDC}$ and $\mathrm{B}$ cell percentages in the BM of transfer recipients. (c) Representative FACS plots of $\mathrm{pDC}$ and B cell percentages in the Spleen of transfer recipients. 
bioRxiv preprint doi: https://doi.org/10.1101/310680; this version posted April 30, 2018. The copyright holder for this preprint (which was not certified by peer review) is the author/funder, who has granted bioRxiv a license to display the preprint in perpetuity. It is made available under aCC-BY-NC-ND 4.0 International license.

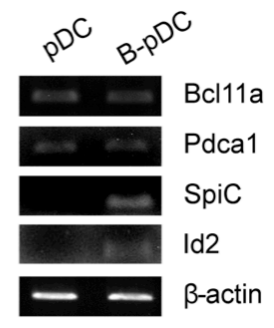

Supplemental Figure 3. RT-PCR confirmation that Bcl11a, Pdca1, SpiC, and Id2 expression match RNAseq trends between $\mathrm{pDC}$ and B-pDC. 
bioRxiv preprint doi: https://doi org/10.1101/310680; this version posted April 30, 2018. The copyright holder for this preprint (which was not certified by peer review) is the author/funder, who has granted bioRxiv a license to display the preprint in perpetuity. It is made available under aCC-BY-NC-ND 4.0 International license.

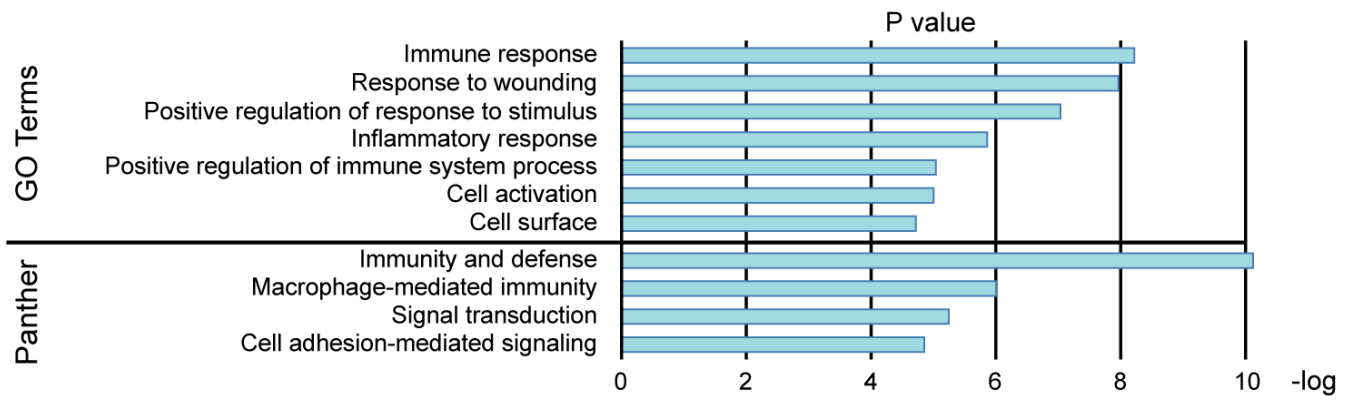

Supplemental Figure 4. GO Term or Panther-derived pathways identified by DAVID analysis of $\sim 220$ differentially expressed genes between the $\mathrm{pDC}$ and B-pDC subsets ${ }^{28,29}$. 

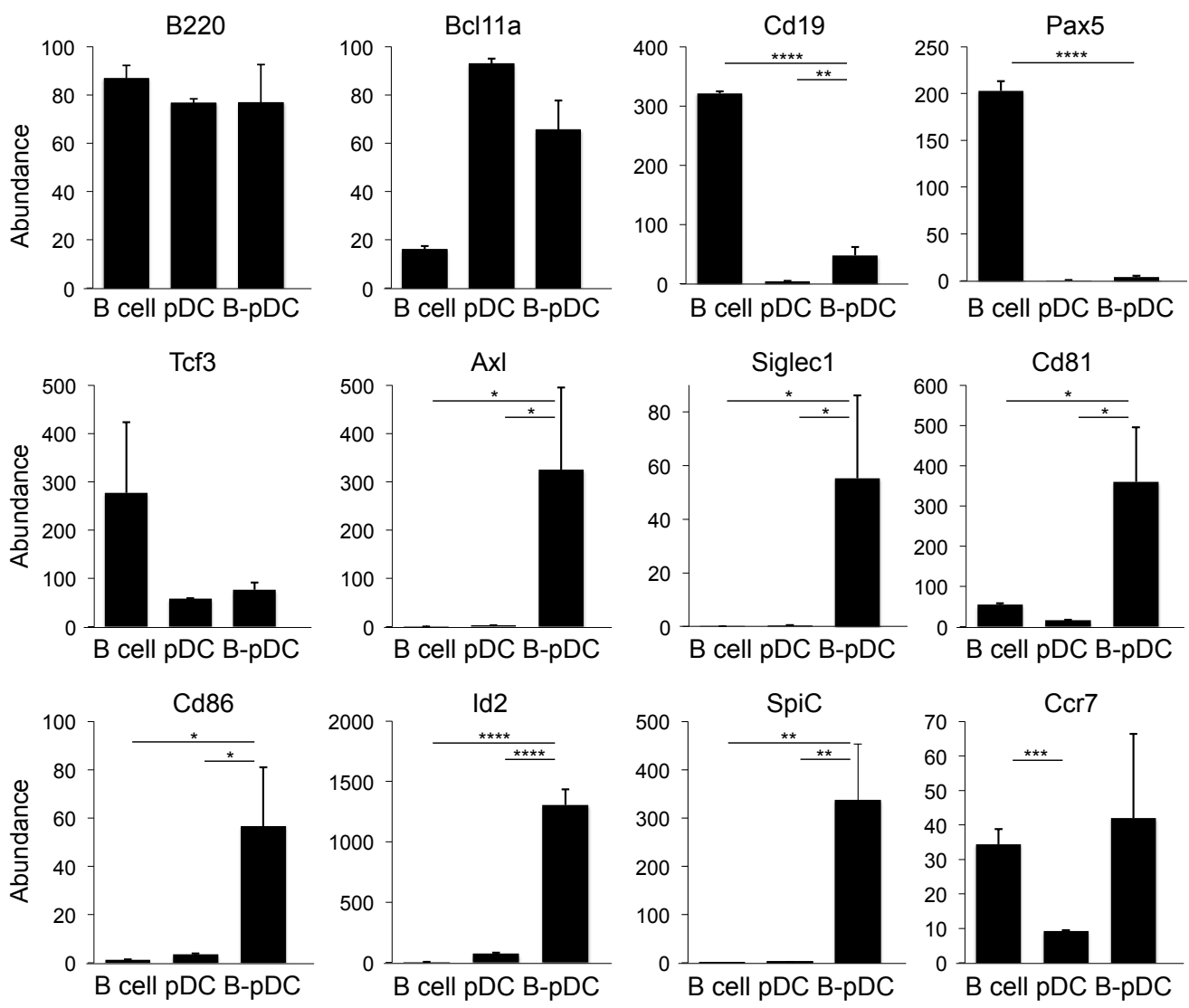

Supplemental Figure 5. Abundance measured as Reads Per Kilobase of transcript per million mapped reads (RPKM) of genes expressed in both B-pDC and B cells (B220, Bcl11a, and Cd19, but not B cell genes Pax5 and Tcf3). Differentially expressed genes in pDC vs B-pDC included Axl, Siglec1, Cd81, Cd86, Id2, SpiC, and Ccr7. ${ }^{*} \mathrm{p}<0.05,{ }^{* *} \mathrm{p}<0.01, * * * \mathrm{p}<0.001, * * * * \mathrm{p}<0.0001$ 

aCC-BY-NC-ND 4.0 International license.
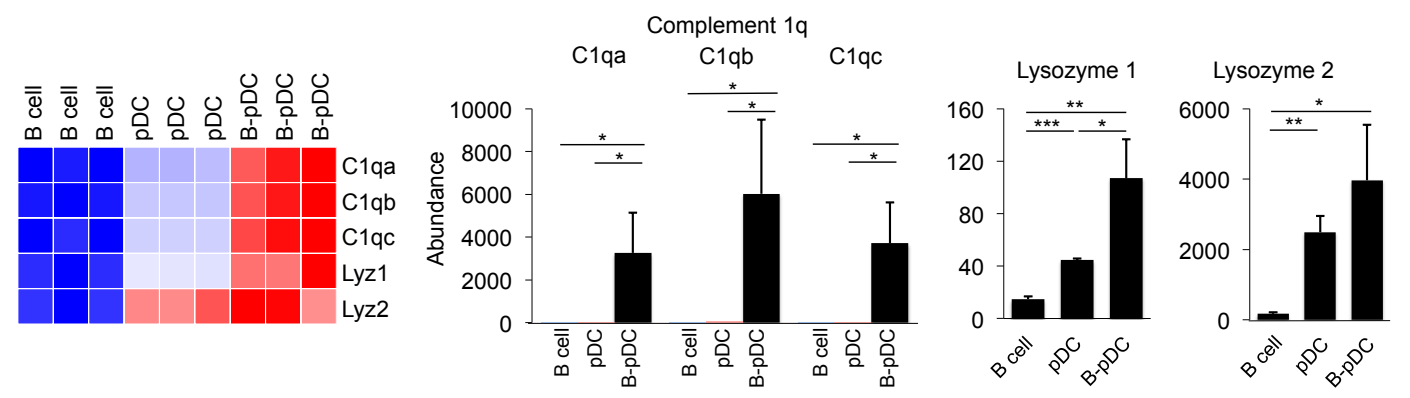

Supplemental Figure 6. Left: expression heatmap of complement 1q genes C1qa, C1qb, and C1qc, and Lysozyme genes Lyz1 and Lyz2 in pro B cells, pDC and B-pDC. Right: Abundance measured as Reads Per Kilobase of transcript per million mapped reads of Complement 1q and Lysozyme genes. ${ }^{*} \mathrm{p}<0.05,{ }^{* *} \mathrm{p}<0.005,{ }^{* * *} \mathrm{p}<0.0005$ 